Review

\title{
Investigational Monoclonal Antibodies in the Treatment of Multiple Myeloma: A Systematic Review of Agents under Clinical Development
}

\author{
Ahmad Iftikhar ${ }^{1}\left(\mathbb{D}\right.$, Hamza Hassan $^{2}$, Nimra Iftikhar ${ }^{3}$, Adeela Mushtaq ${ }^{4}$, Atif Sohail ${ }^{2}$, \\ Nathaniel Rosko ${ }^{5}$ (D), Rajshekhar Chakraborty ${ }^{5}$, Faryal Razzaq ${ }^{6}$, Sonia Sandeep ${ }^{7}$, \\ Jason Neil Valent ${ }^{5}$, Abraham Sebastian Kanate ${ }^{8}$ and Faiz Anwer ${ }^{5, *(D)}$ \\ 1 Department of Internal Medicine, The University of Arizona, Tucson, AZ 85721, USA; \\ ahmad.iftikhar167@gmail.com \\ 2 Department of Internal Medicine, Rochester General Hospital, Rochester, NY 14621, USA; \\ Hamza.Hassan@rochesterregional.org (H.H.); atif.sohailmd@gmail.com (A.S.) \\ 3 Dow University of Health Sciences, Karachi 74200, Pakistan; nimra.b@gmail.com \\ 4 Department of Internal Medicine, University of Pittsburgh Medical Center, McKeesport, PA 16148, USA; \\ adeela_mushtaq@hotmail.com \\ 5 Taussig Cancer Center, Cleveland Clinic, Cleveland, OH 44106, USA; roskon@ccf.org (N.R.); \\ chakrar2@ccf.org (R.C.); valentj3@ccf.org (J.N.V.) \\ 6 Foundation University Medical College, Islamabad 44000, Pakistan; frazzaq90@gmail.com \\ 7 Department of Pathology, Wilson Medical Center, Wilson, NC 27893, USA; soniasandeep123@gmail.com \\ 8 Department of Hematology Oncology, West Virginia University, Morgantown, WV 26506, USA; \\ ASKANATE@hsc.wvu.edu \\ * Correspondence: anwerf@ccf.org; Tel.: +1-216-444-9464
}

Received: 30 March 2019; Accepted: 13 May 2019; Published: 24 May 2019

check for updates

\begin{abstract}
Background: Immunotherapy for multiple myeloma (MM) has been the focus in recent years due to its myeloma-specific immune responses. We reviewed the literature on non-Food and Drug Administration (FDA) approved monoclonal antibodies (mAbs) to highlight future perspectives. We searched PubMed, EMBASE, Web of Science, Cochrane Library and ClinicalTrials.gov to include phase I/II clinical trials. Data from 39 studies (1906 patients) were included. Of all the agents, Isatuximab (Isa, anti-CD38) and F50067 (anti-CXCR4) were the only mAbs to produce encouraging results as monotherapy with overall response rates (ORRs) of $66.7 \%$ and $32 \%$ respectively. Isa showed activity when used in combination with lenalidomide (Len) and dexamethasone (Dex), producing a clinical benefit rate (CBR) of $83 \%$. Additionally, Isa used in combination with pomalidomide (Pom) and Dex resulted in a CBR of 73\%. Indatuximab Ravtansine (anti-CD138 antibody-drug conjugate) produced an ORR of $78 \%$ and $79 \%$ when used in combination with Len-Dex and Pom-Dex, respectively. Conclusions: Combination therapy using mAbs such as indatuximab, pembrolizumab, lorvotuzumab, siltuximab or dacetuzumab with chemotherapy agents produced better outcomes as compared to monotherapies. Further clinical trials investigating mAbs targeting CD38 used in combination therapy are warranted.
\end{abstract}

Keywords: Multiple myeloma; immunotherapy; antibody; targeted therapy; molecular targets; bispecific antibodies; immune checkpoint inhibitors; Antibody Drug Conjugate 


\section{Introduction}

Multiple myeloma (MM) remains an incurable hematologic malignancy. The American Cancer Society estimates 32,110 new cases of MM in the year 2019 with estimated deaths about 12,960 [1]. MM is a multi-clonal disease characterized by significant intra-tumor heterogeneity, which in turn leads to clonal evolution and tiding along the trajectory of disease [2-4]. Despite ongoing efforts to advance MM precision and personalized therapy using next generation sequencing (NGS), whole-genome sequencing (WGS), RNA sequencing (RNA-Seq) and sequencing panels for direct targeting, the field is still in its infancy and its broad clinical applicability remains undetermined. The key treatment strategies currently utilized in contemporary practice consist of three-drug regimens, typically including a proteasome inhibitor (PI), immunomodulatory drug (IMiD) or a mAb, along with dexamethasone. Despite many therapeutic advances, MM patients invariably relapse after a period of remission mainly due to development of resistance to therapy, associated clonal proliferation, and/or sub clonal divergence [5].

Monoclonal antibodies provide an important scaffold for signaling mechanisms, which we classified as follows. (1) Complement dependent cytotoxicity (CDC): The antibodies bind to the tumor cell surface, which stimulates proteolytic enzymes to form a membrane attack complex to kill tumor cells by lysing the cell membrane, [6], (2) Antibody-dependent cellular cytotoxicity (ADCC): mAbs bind to tumor cells by interaction between $F_{c}$ region of an antibody and the Fc receptor on immune cells such as neutrophils, natural killer (NK) cells and macrophages. This subsequent interaction leads to phagocytosis of mAb-tumor cell conjugates with resultant cell lysis by NK cells, [7], (3) mAbs can function as agonists to activate apoptosis, (4) mAbs function as antagonists to block intracellular signaling pathways to stop cell proliferation, (5) Antibody-drug conjugate (ADC) can act as a carrier to transport cytotoxic agents inside tumor cells to cause tumor cell lysis decreasing systemic toxicities [8]. These anti-tumor mechanisms can be achieved by aiming a target (receptor/ligand/chemokine/cytokine) that is either present in the cancer-milieu, trans-membrane or intracellularly.

Monoclonal antibodies have produced favorable results as combination therapy with PIs and IMiDs. Currently, daratumumab (Dara) is Food and Drug Administration (FDA)-approved as monotherapy [9] and combination therapy along with elotuzumab (Elo) for the relapsed and refractory MM (RRMM). Combination therapy trials for RRMM showed improved efficacy for the mAb containing arms such as POLLUX, CASTOR, ELOQUENT-2 and ELOQUENT-3 trials assessing Dara and Elo, respectively, and reported ORR $93 \%$ vs. $76 \%$ (Dara-Rd vs. Rd), $83 \%$ vs. $63 \%$ (Dara-Vd vs. Vd), 79\% vs. $66 \%$ (Elo-Rd vs. Rd) and 53\% vs. $26 \%$ (Elo+Pom+Dex vs Pom+Dex) [10-13]. For newly diagnosed multiple myeloma (NDMM), a multi-center phase III (ALCYONE) trial using daratumumab in a four drug combination of bortezomib, melphalan and prednisone (VMp) showed 18-month PFS of 71.6\% for Dara-VMp versus 50.2\% for VMp alone [14].

The goal of $\mathrm{mAb}$ combination regimens is to deepen initial responses with minimal residual disease-negative status which predicts improved PFS and overall survival (OS) [15]. Unlike many currently approved non-targeted therapies for MM, targeted mAbs help overcome myeloma-associated immune dysregulation [16], synergistically enhance immunomodulation and have the potential to improve immune surveillance. Immune therapies for MM include the use of mAbs targeting the surface or non-surface receptors with naked or linked antibodies, cancer vaccines and adaptive immunotherapy utilizing genetically engineered T-cells (CAR-T) [17].

We reviewed the literature on investigational non-FDA approved mAbs and outlined their pathogenic targets, trial data, reported adverse events and have included a discussion of future perspectives in this drug category. 


\section{Methods}

\subsection{Search Strategy}

We searched PubMed, EMBASE, Web of Science, Cochrane Library and ClinicalTrials.gov on 09/27/2018. While running our search, we applied the last 10 years' filter and excluded non-human studies. We also reviewed bibliographies of review articles to include additional relevant studies.

\subsection{Eligibility Criteria}

This review includes Phase I/II clinical trials of mAbs utilized in the treatment of MM, which were either complete or currently recruiting. We included studies performed in the last ten years (2008-2018) with reported efficacy outcomes. We excluded studies and clinical trials on Dara and Elo as they are already FDA approved for the treatment of RRMM. We excluded review articles and trials with no reported efficacy outcomes.

\subsection{Study Selection and Data Extraction}

We screened articles based on titles/abstracts first and later by reading full texts of eligible articles by two reviewers independently $(\mathrm{HH} / \mathrm{NI})$. We used a data extraction form in Excel to extract data such as author, study design, year, the total number of patients, target receptor, antibody, antibody drug regimen, median prior lines of therapy, dosage, number of dosage cycles, efficacy outcomes and adverse outcomes. For most of the studies, the primary outcome extracted was overall response rate (ORR) and overall response (OR). With respect to clinical outcomes, we collected complete response (CR), stable disease (SD), partial response (PR), progressive disease (PD), overall survival (OS) and progression-free survival (PFS) rates. Regarding toxicities and adverse outcomes, we extracted data about common adverse events and $>$ grade III toxicities.

\section{Results}

We identified 2730 studies using PubMed (90), Cochrane (150), EMBASE (725), SCOPUS (1749) and ClinicalTrials.gov (16). After excluding 335 duplicates, we read titles and abstracts of the remaining 2395 articles and excluded an additional 2298 articles that were review articles, expert opinions, preclinical studies, monoclonal antibodies targeting cancers other than MM and studies on daratumumab and Elotuzumab. We read full-length manuscripts of the remaining 97 articles and excluded 58 articles based on the following reasons: no efficacy outcomes reported (15), interim analysis (10), preclinical studies (28), review articles (5). Thirty-Nine (39) clinical trials that met our inclusion criteria included 1906 patients. (Figure 1: PRISMA flow diagram).

We evaluated the following surface receptor antibodies ( $n$ denotes the number of studies): Dacetuzumab (anti-CD40, $n=2$ ), Lucatumumab (anti-CD40, $n=1$ ), Isatuximab (anti-CD38, $n=6$ ), MOR202 (anti-CD38, $n=1$ ), IPH 2101 (anti-KIR, $n=2$ ), Milatuzumab (anti CD74, $n=1$ ), BI-505 (anti-ICAM1, $n=1$ ), Figitumumab (anti-IGF1, $n=1$ ), AVE 1642 (anti-IGF1, $n=1$ ), PAT SM6 (anti-GRP-78, $n=1)$. (Table 1).

We also evaluated the following Non-surface receptor antibodies: Bevacuzumab (anti-VEGF, $n=2$ ), Siltuximab (anti-IL6, $n=5$ ), Atacicept (anti-BAFF, $n=1$ ), Tabalumab (anti-BAFF, $n=2$ ), Nivolumab (anti-PD-1, $n=2$ ), Pembrolizumab (anti-PD-1, $n=2$ ), Pidilizumab (anti-PD-1, $n=1$ ), F50067 (anti-CXR4, $n=1$ ), Napatumumab (anti-TRAILR, $n=1$ ), Lorvotuzumab (anti-CD56, $n=2$ ), Indatuximab Ravtansine (anti-CD138 antibody drug conjugate, $n=3$ ) (Table 2).

We summarized adverse effects related to mAb drugs in Table 3. 


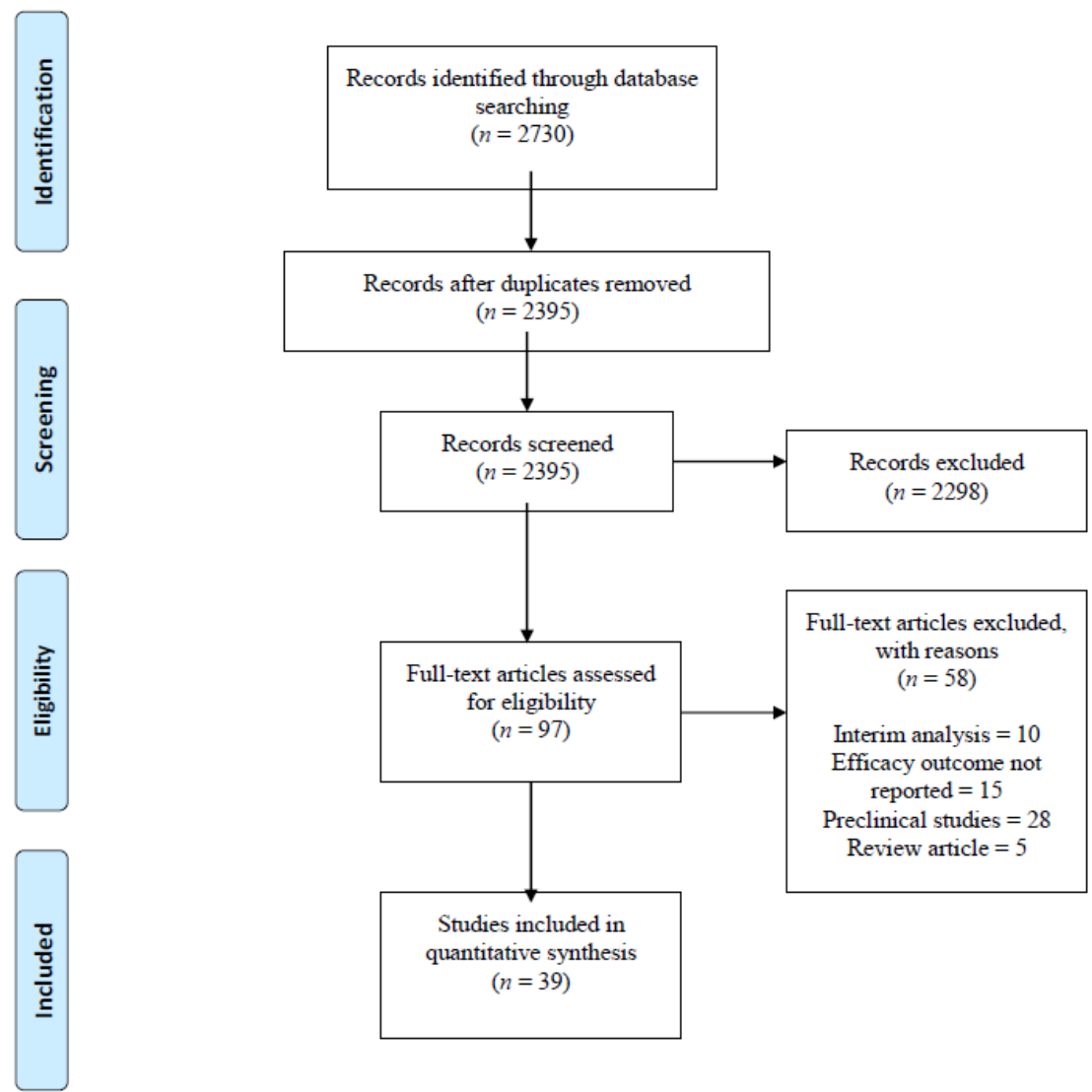

Figure 1. PRISMA flow diagram. Records identified through PubMed, Embase, Cochrane, SCOPUS and Clinical.Trials.gov database searches. 
Table 1. Surface receptor targeting antibodies in relapsed refractory multiple myeloma.

\begin{tabular}{|c|c|c|c|c|c|c|c|c|}
\hline $\begin{array}{l}\text { Author, Year, } \\
\text { Study Design, } \\
\text { Journal. }\end{array}$ & No of Patients & Antibody & Target & Regimen & $\begin{array}{l}\text { Median Prior } \\
\text { Therapies }\end{array}$ & Dose & No. of Cycles & Clinical Outcome \\
\hline $\begin{array}{l}\text { Agura, 2009, } \\
\text { Phase 1b, Blood. }\end{array}$ & 36/33 (REP) & Dacetuzumab (IgG1) & $\mathrm{CD}-40$ & Dac + Len + Dex & 4 & $4-12 \mathrm{mg} / \mathrm{kg}$ & 4 & $\begin{array}{c}\mathrm{OR}=39 \%, \mathrm{CR}=3 \% \\
\mathrm{PR}=33 \%, \mathrm{MR}=12 \% \\
\mathrm{SD}=30 \%, \mathrm{PD}=6 \% \\
\mathrm{NE}=12 \%\end{array}$ \\
\hline $\begin{array}{l}\text { Husein, } 2010 . \\
\text { Phase I, } \\
\text { Haematologica. }\end{array}$ & 44 & Dacetuzumab (IgG1) & $\mathrm{CD}-40$ & $\begin{array}{l}\text { Dacetuzumab } \\
\text { Monotherapy }\end{array}$ & $5(2-14)$ & $4-12 \mathrm{mg} / \mathrm{kg}$ & $4-5$ & $\mathrm{SD}=20 \%$ \\
\hline $\begin{array}{l}\text { Bensinger, 2012, } \\
\text { Phase I, British } \\
\text { Journal of } \\
\text { Haematology. }\end{array}$ & 28 & Lucatumumab (IgG1) & CD-40 & $\begin{array}{l}\text { Lucatumumab } \\
\text { Monotherapy }\end{array}$ & NR & $1-6 \mathrm{mg} / \mathrm{kg}$ & 4 & $\mathrm{SD}=43 \%, \mathrm{PR}=4 \%>8 \mathrm{~m}$ \\
\hline $\begin{array}{l}\text { Martin, 2014, } \\
\text { Phase I, ASH. }\end{array}$ & 35 & $\begin{array}{c}\text { Isatuximab } \\
\text { (SAR650984) } \\
\text { (IgG1-kappa) }\end{array}$ & $\mathrm{CD}-38$ & $\begin{array}{l}\text { Isatuximab } \\
\text { Monotherapy }\end{array}$ & $6(2-14)$ & $0.1-20 \mathrm{mg} / \mathrm{kg}$ & $5-7$ & $\begin{array}{c}\mathrm{ORR}=32 \%(>10 \mathrm{mg}) \\
\mathrm{PR}=6, \mathrm{CR}=2\end{array}$ \\
\hline $\begin{array}{l}\text { Richter, 2016, } \\
\text { Phase II, ASCO. }\end{array}$ & 97 & $\begin{array}{l}\text { Isatuximab SAR650984 } \\
\text { (IgG1-kappa) }\end{array}$ & $\mathrm{CD}-38$ & $\begin{array}{l}\text { Isatuximab } \\
\text { Monotherapy }\end{array}$ & $5(2-14)$ & $3-10 \mathrm{mg} / \mathrm{kg}$ & NR & $\begin{array}{c}\text { ORR }=24 \% \text { at dose }> \\
10 \mathrm{mg} / \mathrm{kg}\end{array}$ \\
\hline $\begin{array}{l}\text { Martin, 2014, } \\
\text { Phase Ib, ASH. }\end{array}$ & 31 & $\begin{array}{l}\text { Isatuximab SAR650984 } \\
\text { (IgG1-kappa) }\end{array}$ & CD-38 & SAR + Len + Dex & $6(2-12)$ & $3,5,10 \mathrm{mg} / \mathrm{kg}$ & NR & $\begin{array}{c}\mathrm{ORR}=64.5 \%, \mathrm{CBR}=70.8 \%, \\
\mathrm{SCR}=6 \%, \mathrm{VGPR}=26 \%, \\
\mathrm{PR}=32 \%, \mathrm{PFS}=6.2 \mathrm{~m}\end{array}$ \\
\hline $\begin{array}{l}\text { Martin, Phase } \\
\mathrm{Ib}, 2017 \text {, Blood. }\end{array}$ & 57 & $\begin{array}{l}\text { Isatuximab } \\
\text { (IgG1-kappa) }\end{array}$ & CD-38 & Isatuximab + Len + Dex & $5[1-12]$ & $\begin{array}{c}3,5 \text { or } 10 \mathrm{mg} / \mathrm{kg} \\
{[\mathrm{Q} 2 \mathrm{~W}] \text { or } 10 \text { or }} \\
20 \mathrm{mg} / \mathrm{kg} \\
\text { weekly }\end{array}$ & $9(1-37)$ & $\begin{aligned} \mathrm{ORR}= & 56 \%(29 / 52), \mathrm{mPFS} \\
& 8.5 \text { months }\end{aligned}$ \\
\hline $\begin{array}{l}\text { Lendvai, 2016, } \\
\text { Phase Ib, } \\
\text { Haematologica }\end{array}$ & 26 & $\begin{array}{l}\text { Isatuximab } \\
\text { (IgG1-kappa) } \\
\text { Isatuximab } \\
\text { (IgG1-kappa) }\end{array}$ & $\begin{array}{l}\text { CD-38 } \\
\text { CD-38 }\end{array}$ & $\begin{array}{c}\text { Isatuximab+ } \\
\text { Lenalidomide+ Dexa } \\
\text { Isatuximab + } \\
\text { Lenalidomide + Dexa }\end{array}$ & $\begin{array}{l}4.5(1-8) \\
6(3-10)\end{array}$ & $\begin{array}{c}10 \mathrm{mg} / \mathrm{kg}+ \\
25 \mathrm{mg}+40 \mathrm{mg} \\
20 \mathrm{mg} / \mathrm{kg}+ \\
25 \mathrm{mg}+40 \mathrm{mg}\end{array}$ & NR & $\begin{array}{c}\text { ORR: 50\%, VGPR: } 25 \% \text {, PR: } \\
\text { 25\% CBR (m > MR): } 83 \% \\
\text { ORR: } 50 \% \text {, VGPR: } 20 \% \text {, PR: } \\
\text { 30\% CBR (m > MR): } 50 \%\end{array}$ \\
\hline $\begin{array}{l}\text { Mikhael, 2017, } \\
\text { Phase Ib, } \\
\text { Haematologica. }\end{array}$ & 26 & $\begin{array}{l}\text { Isatuximab } \\
\text { (IgG1-kappa) }\end{array}$ & CD-38 & $\begin{array}{c}\text { Isatuximab + } \\
\text { Pomalidomide + Dexa }\end{array}$ & $4(2-11)$ & $\begin{array}{l}5,10,20 \mathrm{mg} / \mathrm{kg}+ \\
4 \mathrm{mg}+40 \mathrm{mg}\end{array}$ & NR & $\begin{array}{l}\text { CBR: } 73 \%, \text { PR: } 62 \%(n=16) \\
\{C R=1 ; \text { VGPR }=8, P R=7\}\end{array}$ \\
\hline
\end{tabular}


Table 1. Cont.

\begin{tabular}{|c|c|c|c|c|c|c|c|c|}
\hline $\begin{array}{l}\text { Author, Year, } \\
\text { Study Design, } \\
\text { Journal. }\end{array}$ & No of Patients & Antibody & Target & Regimen & $\begin{array}{l}\text { Median Prior } \\
\text { Therapies }\end{array}$ & Dose & No. of Cycles & Clinical Outcome \\
\hline \multirow{3}{*}{$\begin{array}{l}\text { Raab, 2016, } \\
\text { Phase I/IIa, } \\
\text { Blood. }\end{array}$} & 16 REP & MOR202 (IgG $\lambda)$ & CD-38 & MOR202 monotherapy & 4 & $\begin{array}{c}\text { 4, } 8 \text { and } \\
16 \mathrm{mg} / \mathrm{kg} \\
\text { weekly. }\end{array}$ & NR & PR 19\%, VGPR 13\% \\
\hline & 7/5 (REP) & MOR202 (IgG $\lambda)$ & CD-38 & MOR202 + LEN cohort & 4 & $\begin{array}{c}4,8 \text { and } \\
16 \mathrm{mg} / \mathrm{kg} \\
\text { weekly. } \\
4,8 \text { and }\end{array}$ & NR & PR $71 \%$ \\
\hline & 5/3 (REP) & MOR202 IgG $\lambda$ ) & CD-38 & MOR202 + POM & 4 & $\begin{array}{l}16 \mathrm{mg} / \mathrm{kg} \\
\text { weekly. }\end{array}$ & NR & $C R=2$ \\
\hline $\begin{array}{c}\text { Benson, 2015, } \\
\text { phase I, Clinical } \\
\text { Cancer } \\
\text { Research. }\end{array}$ & 15 & IPH 2101 (IgG4) & KIR & $\begin{array}{l}\text { IPH } 2101+\text { Len } \\
\quad(10-25 \mathrm{mg})\end{array}$ & $1-2$ & $0.2-2 \mathrm{mg} / \mathrm{kg}$ & 4 & $\begin{array}{l}\text { VGPR } 13 \% \text {, PR } 20 \% \text {, MR } \\
7 \% \text {, SD } 40 \% \text {, PD } 20 \%\end{array}$ \\
\hline $\begin{array}{l}\text { Benson, 2012, } \\
\text { Phase I, Blood. } \\
\text { Kaufman, 2013, }\end{array}$ & 32 & IPH 2101 (IgG4) & KIR & IPH 2101 Monotherapy & $2(1-7)$ & $\begin{array}{c}0.0003-3 \mathrm{mg} / \mathrm{kg} \\
\text { every } 28 \text { days }\end{array}$ & 4 & No ORR, SD $n=11(34 \%)$ \\
\hline $\begin{array}{l}\text { Phase I, British } \\
\text { Journal of } \\
\text { Haematology. }\end{array}$ & 25 & $\begin{array}{l}\text { Milatuzumab } \\
\text { (IgG1-kappa) }\end{array}$ & CD74 & IPH 2101 Monotherapy & 5 & $\begin{array}{c}1.5-16 \mathrm{mg} / \mathrm{kg} \times \\
2 \text { or } 4 \text { weeks }\end{array}$ & 8 & $\begin{array}{c}\text { No ORR, SD }=26 \%(5 / 19) \\
\quad>3 \mathrm{~m},(1 / 19)>17 \mathrm{~m}\end{array}$ \\
\hline $\begin{array}{c}\text { Hansson, 2015, } \\
\text { Phase I, Clinical } \\
\text { Cancer } \\
\text { Research. }\end{array}$ & 35/29 (REP) & BI-505 (IgG1) & ICAM-1 & BI-505 Monotherapy & 6 & $\begin{array}{l}0.0004 \text { to } \\
20 \mathrm{mg} / \mathrm{kg}\end{array}$ & $1-2$ & $\mathrm{SD}=24 \%(2 \mathrm{~m}), \mathrm{PD}=65 \%$ \\
\hline \multirow{2}{*}{$\begin{array}{l}\text { Lacy, 2008, } \\
\text { Phase I, Journal } \\
\text { of Clinical } \\
\text { Oncology. }\end{array}$} & 47 & $\begin{array}{c}\text { Figitumumab (CP } \\
751,871) \operatorname{IgG} 2\end{array}$ & IGF-1 & $\begin{array}{l}\text { Figitumumab }+ \text { Dex if } \\
\text { no PR on figitumumab } \\
\text { monotherapy }\end{array}$ & $4(0-8)$ & $\begin{array}{l}0.025-20 \mathrm{mg} / \mathrm{kg} \\
\text { for } 4 \text { weeks }\end{array}$ & 4 & No objective response \\
\hline & 27 & $\begin{array}{c}\text { Figitumumab (CP } \\
751,871) \operatorname{IgG} 2\end{array}$ & IGF-1 & Figitumumab + Dex & $4(0-8)$ & $\begin{array}{c}0.025-20 \mathrm{mg} / \mathrm{kg} \\
\text { for } 4 \text { weeks }+ \\
40 \mathrm{mg} / \text { day Dex }\end{array}$ & & $\mathrm{PR}=6$ \\
\hline \multirow{2}{*}{$\begin{array}{c}\text { Moreau, 2011, } \\
\text { Phase I, } \\
\text { Leukemia. }\end{array}$} & 15 & AVE1642 (IgG1) & IGF-1 & AVE1642 monotherapy & 4 & $3-18 \mathrm{mg} / \mathrm{kg}$ & 2 & $\mathrm{MR}=1, \mathrm{SD}=7, \mathrm{PD}=4$ \\
\hline & 11 & AVE1642 (IgG1) & IGF-1 & AVE1642 + Bortezomib & 4 & $\begin{array}{c}0.5-12 \mathrm{mg} / \mathrm{kg} \text { + } \\
1.3 \mathrm{mg} / \mathrm{m}^{2}\end{array}$ & 4 & $\mathrm{CR}=1, \mathrm{PR}=1, \mathrm{SD}=3$ \\
\hline $\begin{array}{c}\text { Rasche, 2015, } \\
\text { Phase I, } \\
\text { Haematologica. }\end{array}$ & 12 & PAT-SM6 (IgM) & GRP-78 & PAT-SM6 & $3.9(2-7)$ & $1,3,6 \mathrm{mg} / \mathrm{kg} /$ day & 4 & No OR, SD: 33.3\% \\
\hline
\end{tabular}

Abbreviations: REP; Response evaluable patients, Len; Lenalidomide, Dex; Dexamethasone, KIR; Killer-cell immunoglobulin like receptor, ORR; Objective response rate, CR; Complete response, PR: partial response, VGPR; Very good partial response, MR; Minimal response, PD; Progressive disease, NE; Not evaluable, PFS; progression free survival, m; months. GRP: Glucose regulated protein, ASH; American Society of Hematology, ASCO; American Society of Clinical Oncology. 
Table 2. Non-surface receptor Antibodies targeting in Relapsed Refractory Multiple Myeloma.

\begin{tabular}{|c|c|c|c|c|c|c|c|c|}
\hline $\begin{array}{l}\text { Author, Year, Study } \\
\text { Design }\end{array}$ & No of Patients & Antibody & Target & $\begin{array}{l}\text { Median Prior } \\
\text { Therapies }\end{array}$ & Dose & No. of Cycles & Regimen & Outcome \\
\hline Callander, 2009, NEJM. & 31/27(REP) & $\begin{array}{l}\text { Bevacizumab } \\
\text { (IgG1-kappa) }\end{array}$ & VEGF & $3(1-7)$ & $\begin{array}{l}\text { Bevacizumab } \\
10 \mathrm{mg} / \mathrm{kg} \times 2 \text { weeks }\end{array}$ & 4 & $\begin{array}{l}\text { Bevacizumab + Len (25mg) } \\
\text { + Dex (40mg) }\end{array}$ & $\begin{array}{l}\mathrm{OR}=70 \%, \mathrm{CR}=15 \% \\
\mathrm{PR}=56 \%, \mathrm{PD}=11 \%\end{array}$ \\
\hline \multirow{2}{*}{$\begin{array}{l}\text { Somlo, 2011, Phase II, } \\
\text { British Journal of } \\
\text { Haematology. }\end{array}$} & 6 & $\begin{array}{l}\text { Bevacizumab } \\
\text { (IgG1-kappa) }\end{array}$ & VEGF-A & $3(0-5)$ & $\begin{array}{l}\text { Bevacizumab } \\
10 \mathrm{mg} / \mathrm{kg}\end{array}$ & 4 & Bevacizumab Monotherapy & $\begin{array}{l}\mathrm{PD}=29-69 \text { days } \\
\mathrm{SD}=238 \text { days, } \mathrm{SD}=16.6 \% \\
\mathrm{PD}=83 \%\end{array}$ \\
\hline & 6 & $\begin{array}{l}\text { Bevacizumab } \\
\text { (IgG1-kappa) } \pm \\
\text { Thalidomide }\end{array}$ & VEGF-A & & & 4 & $\begin{array}{l}\text { Bevacizumab } \pm \\
\text { Thalidomide }\end{array}$ & $\begin{array}{l}\mathrm{SD}=37-350 \text { days }, \mathrm{PR}=33 \% \\
\mathrm{PD}=67 \%\end{array}$ \\
\hline \multirow[t]{2}{*}{$\begin{array}{l}\text { White, 2013, Phase II, } \\
\text { Cancer. }\end{array}$} & 49 & $\begin{array}{l}\text { Bevacizumab } \\
\text { (IgG1-kappa) }\end{array}$ & VEGF & $(1-3)$ & $\begin{array}{l}\text { Bevacizumab } \\
15 \mathrm{mg} / \mathrm{kg} \text { I.V }\end{array}$ & 8 & Bevacizumab + Bor & \multirow{7}{*}{$\begin{array}{l}\text { ORR }=51 \%, \mathrm{PR}=16.3 \%, \\
\mathrm{mPFS}=6.2 \mathrm{~m} \\
\mathrm{ORR}=43.4 \%, \mathrm{PR}=7.5 \%, \\
\mathrm{mPFS}=5.1 \mathrm{~m} \\
1 \text {-yr PFS } 84.5 \% \text { with siltuximab } \\
\text { vs. } 74.4 \% \text { with placebo. } \\
\mathrm{mPFS}=8 \mathrm{~m}, \mathrm{ORR}=55 \%, \\
\mathrm{CR}=11 \%, \mathrm{OS}=30.8 \mathrm{~m} \\
\mathrm{mPFS}=7.6, \mathrm{ORR}=47 \%, \\
\mathrm{CR}=7 \%, \mathrm{OS}=36.8 \mathrm{~m} \\
\text { No Response }(\mathrm{CR} / \mathrm{PR}) \\
\mathrm{SD}=62 \%, \mathrm{PD}=39 \% \\
\mathrm{ORR}=23 \%, \mathrm{PR}=17 \%, \\
\mathrm{MR}=6 \%, \mathrm{SD}=57 \%, \mathrm{PD}=17 \%, \\
\mathrm{PFS}=3.7 \mathrm{~m}\end{array}$} \\
\hline & 53 & Placebo & & & Bor $1.3 \mathrm{mg} / \mathrm{m}^{2}$ & & Placebo + Bor & \\
\hline $\begin{array}{l}\text { Brighton, 2017, Phase II, } \\
\text { ASH. }\end{array}$ & 74 & $\begin{array}{l}\text { Siltuximab } \\
\text { (IgG1) }\end{array}$ & IL-6 & NR & $\begin{array}{l}15 \mathrm{mg} / \mathrm{kg} \text { Q4 week } \\
\text { vs. Placebo }\end{array}$ & NR & Siltuximab vs. placebo & \\
\hline \multirow{2}{*}{$\begin{array}{l}\text { Orlowski, 2015, Phase } \\
\text { II, American Journal of } \\
\text { Hematology. }\end{array}$} & 142 & $\begin{array}{l}\text { Siltuximab } \\
\text { (IgG1) }\end{array}$ & \multirow[t]{2}{*}{ IL-6 } & \multirow[t]{2}{*}{$1-3$} & Siltuximab $6 \mathrm{mg} / \mathrm{kg}$ & 4 & Siltuximab + Bor & \\
\hline & 139 & Placebo & & & Placebo & & Placebo + Bor & \\
\hline \multirow{2}{*}{$\begin{array}{l}\text { Voorhesse, 2009, Phase } \\
\text { II, British Journal of } \\
\text { Haematology. }\end{array}$} & 14 & $\begin{array}{l}\text { Siltuximab } \\
\text { (IgG1) }\end{array}$ & \multirow[t]{2}{*}{ IL-6 } & \multirow[t]{2}{*}{4} & $6 \mathrm{mg} / \mathrm{kg}$ & \multirow[t]{2}{*}{4} & Siltuximab monotherapy & \\
\hline & 39 & $\begin{array}{l}\text { Siltuximab } \\
\text { (IgG1) }\end{array}$ & & & $6 \mathrm{mg} / \mathrm{kg}+40 \mathrm{~g}$ & & Siltuximab + Dex & \\
\hline $\begin{array}{l}\text { Suzuki, 2015, Phase I, } \\
\text { International Journal of } \\
\text { Hematology. }\end{array}$ & 9 & $\begin{array}{l}\text { Siltuximab } \\
\text { (IgG1) }\end{array}$ & IL-6 & $1-2$ & $5.5 / 11 \mathrm{mg} / \mathrm{kg}$ & $\geq 9$ & $\begin{array}{l}\text { Siltuximab + Bor } \\
\left(1.3 \mathrm{mg} / \mathrm{m}^{2}\right)+\operatorname{Dex}(20 \mathrm{mg})\end{array}$ & $\mathrm{CR}=22 \%, \mathrm{PR}=44 \%$ \\
\hline $\begin{array}{l}\text { Rossi,2009, Phase I, } \\
\text { British Journal of } \\
\text { Cancer. }\end{array}$ & 12/11(REP) & Atacicept (IgG) & BAFF & NR & $2-10 \mathrm{mg} / \mathrm{kg}$ & 5 & Atacicept monotherapy & No ORR, $\mathrm{PD}=54 \%$, SD $=45 \%$ \\
\hline \multirow[t]{2}{*}{$\begin{array}{l}\text { Lida, 2016, Phase I, } \\
\text { Cancer Science. }\end{array}$} & 4 & $\begin{array}{l}\text { Tabalumab } \\
\text { (IgG4) }\end{array}$ & BAFF & At least 1 & $\begin{array}{l}100 \mathrm{mg}+1.3 \mathrm{mg} / \mathrm{m}^{2} \\
+20 \mathrm{mg}\end{array}$ & $3(2-11)$ & Tabalumab + Bor+ Dexa & \multirow{2}{*}{$\begin{array}{l}\text { ORR: } 100 \%, \text { VGPR: } 50 \%(n=2) \text {, } \\
\text { PR: } 50 \%(n=2) \\
\text { ORR: } 41.7 \% \text {, VGPR: } 8.3 \% \\
(n=1), \text { PR:33.3 } \%(n=4), \\
\text { SD: } 16,7 \%(n=2), \\
\text { PD: } 25 \%(n=3)\end{array}$} \\
\hline & 12 & $\begin{array}{l}\text { Tabalumab } \\
\text { (IgG4) }\end{array}$ & BAFF & At least 1 & $\begin{array}{l}200 \mathrm{mg}+1.3 \mathrm{mg} / \mathrm{m}^{2} \\
+20 \mathrm{mg}\end{array}$ & $4.5(1-15)$ & Tabalumab + Bor + Dexa & \\
\hline
\end{tabular}


Table 2. Cont.

\begin{tabular}{|c|c|c|c|c|c|c|c|c|}
\hline $\begin{array}{l}\text { Author, Year, Study } \\
\text { Design }\end{array}$ & No of Patients & Antibody & Target & $\begin{array}{l}\text { Median Prior } \\
\text { Therapies }\end{array}$ & Dose & No. of Cycles & Regimen & Outcome \\
\hline Reje, 2017, Phase II, & 74 & $\begin{array}{l}\text { Tabalumab } \\
\text { (IgG4) }\end{array}$ & BAFF & \multirow{3}{*}{$1-3$} & $100 \mathrm{mg}$ & \multirow{3}{*}{8 or 10} & $\mathrm{Tab}+$ Bor + Dex & $\mathrm{ORR}=58.1 \%$ \\
\hline $\begin{array}{l}\text { British Journal of } \\
\text { Haematology. }\end{array}$ & 74 & $\begin{array}{l}\text { Tabalumab } \\
\text { (IgG4) }\end{array}$ & BAFF & & $300 \mathrm{mg}$ & & Tab + Bor + Dex & $\mathrm{ORR}=59.5 \%$ \\
\hline & 72 & Placebo & & & no $\mathrm{mAb}$ & & Placebo + Bor + Dex & \multirow{2}{*}{$\begin{array}{l}\mathrm{ORR}=61.6 \% \\
\mathrm{mPFS}=10 \mathrm{wk}=\mathrm{K} 8, \mathrm{OR}=4 \% \\
\mathrm{SD}=63 \%, \mathrm{CR}=4 \%\end{array}$} \\
\hline $\begin{array}{l}\text { Lesokhin, 2016, Phase } \\
\text { Ib, JCO. }\end{array}$ & 27 & $\begin{array}{l}\text { Nivolumab } \\
\text { (IgG4) }\end{array}$ & PD-1 & $3(1-12)$ & $1-3 \mathrm{mg} / \mathrm{kg} \times 2 \mathrm{wk}$ & NR & Nivolumab monotherapy & \\
\hline $\begin{array}{l}\text { Ansell, 2016, Phase I, } \\
\text { ASH. }\end{array}$ & 7 & $\begin{array}{l}\text { Nivolumab } \\
\text { (IgG4) }+ \\
\text { Ipilimumab } \\
\text { (IgG1) }\end{array}$ & $\begin{array}{l}\text { PD-1 + } \\
\text { CTLA-4 }\end{array}$ & 5 (range 2-20) & $\begin{array}{l}3 \mathrm{mg} / \mathrm{kg} \text { IV and } \\
1 \mathrm{mg} / \mathrm{kg} \text { IV every } \\
3 \text { weeks } \times \\
4 \text { followed by Nivo } \\
3 \mathrm{mg} / \mathrm{kg} \text { every } \\
2 \text { week for up to } \\
2 \text { years. }\end{array}$ & NR & Nivolumab + Ipilimumab & $\begin{array}{l}\mathrm{mPFS}=2.2, \mathrm{mOS}=7.6, \mathrm{No} \\
\text { ORR. SD } 1(14 \%)\end{array}$ \\
\hline $\begin{array}{l}\text { Badros, 2017, Phase II, } \\
\text { Blood. }\end{array}$ & 48 & $\begin{array}{l}\text { Pembrolizumab } \\
\text { (IgG4) }\end{array}$ & PD-1 & $3(2-5)$ & $200 \mathrm{mg}$ IV $\times 2 \mathrm{wk}$ & 28 & $\begin{array}{l}\text { Pembrolizumab + pom + } \\
\text { Dex }\end{array}$ & $\begin{array}{l}27 \text { of } 48 \text { pts }(56 \%) \text { ORR > PR; } \\
\text { SCR }(\mathrm{n}=4,8 \%), \operatorname{nCR}(n=3 \\
6 \%), \operatorname{VGFR~}(n=6,13 \%), \text { PR } \\
(n=14,29 \%) .\end{array}$ \\
\hline $\begin{array}{l}\text { Ribrag, 2017, Phase Ib, } \\
\text { Haematologica. }\end{array}$ & 30 & $\begin{array}{l}\text { Pembrolizumab } \\
\text { (IgG4) }\end{array}$ & PD-L1 & $4(2-12)$ & $\begin{array}{l}100-200 \mathrm{mg} / \mathrm{kg} \\
\text { Qweek or Q 2week. }\end{array}$ & $6(2-15)$ & $\begin{array}{l}\text { Pembrolizumab } \\
\text { monotherapy }\end{array}$ & SD: $57 \%$. PD: $43 \%$. \\
\hline $\begin{array}{l}\text { Efebera, 2015, Phase I/II, } \\
\text { Blood. }\end{array}$ & 12 & $\begin{array}{l}\text { Pidilizumab } \\
\text { (IgG4) }\end{array}$ & PD-1 & $2(2-11)$ & $\begin{array}{l}1.5-6 \mathrm{mg} / \mathrm{kg} \text { every } \\
28 \text { days }\end{array}$ & NR & $\begin{array}{l}\text { Pidilizumab + Len } \\
\text { (15-25mg) }\end{array}$ & VGPR $n=3$, PR $n=1$ \\
\hline $\begin{array}{l}\text { Fouquet, 2018, Phase I, } \\
\text { Oncotarget. }\end{array}$ & 10/6 (REP) & F50067 (IgG1) & CXCR4 & NR & 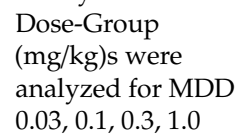 & 21 & F50067 Monotherapy & $\begin{array}{l}\text { ORR } 66.7 \% \text { (>PR). } \\
\text { Objective response } 66.7 \% \\
(>\mathrm{SD})\end{array}$ \\
\hline \multirow{4}{*}{$\begin{array}{l}\text { Belch, 2011, Phase II, } \\
\text { Haematologica. }\end{array}$} & 4/3 (REP) & F50067 (IgG1) & CXCR4 & NR & $\begin{array}{l}0.03,0.1 \text {. weekly or } \\
\text { Q2 week }\end{array}$ & 15 & F50067 + Len-LoDex & \multirow{4}{*}{$\begin{array}{l}\text { Objective response } 33.3 \% \text { ( }>\text { SD } \\
\text { ORR not available } \\
\text { ORR } 51.4 \% \text { Median DOR } 8.5 \mathrm{~m} \\
\text { PR } 18 . \\
\text { Mean PFS } 8.7 \text { CI }(7.6,10.0) \\
\text { ORR 30.3\%, Median DOR } \\
\text { 9.3 m. PR 10. } \\
\text { Mean PFS 4.7 CI }(2.5,7.4) \\
p=0.29 \\
\text { ORR 52.8\%, Median DOR } \\
7.6 \mathrm{~m} \text {. PR } 17 \\
\text { Mean PFS } 5.7 \mathrm{CI}(5.2,8.9) \\
p=0.21\end{array}$} \\
\hline & Arm A $=35$ & $\begin{array}{l}\text { No mAb, only } \\
\text { Bor }\end{array}$ & TRAILR1 & 1.6 & $\begin{array}{l}\text { Velcade Dose: } \\
1.3 \mathrm{mg} / \mathrm{m}^{2} \text { on days } \\
1,4,8,11 \mathrm{Q} 21 \mathrm{D}\end{array}$ & $\begin{array}{l}\text { Maximum } \\
17 \text { cycles (1year) }\end{array}$ & Bor & \\
\hline & Arm B10 = 33 & $\begin{array}{l}\text { Mapatumumab } \\
\text { (IgG1) }\end{array}$ & TRAILR1 & 1.6 & $\begin{array}{l}10 \mathrm{mg} / \mathrm{kg} \text { on } \\
\mathrm{d} 1 \mathrm{Q} 21 \text { days }\end{array}$ & $\begin{array}{l}\text { Maximum of } \\
17 \text { cycles (1year) }\end{array}$ & Bor + Mapatumumab & \\
\hline & Arm B20 $=36$ & $\begin{array}{l}\text { Mapatumumab } \\
\text { (IgG1) }\end{array}$ & TRAILR1 & 1.6 & $\begin{array}{l}20 \mathrm{mg} / \mathrm{kg} \text { on Day } \\
1 \text { Q21 days }\end{array}$ & $\begin{array}{l}\text { Maximum of } \\
17 \text { cycles (1year) }\end{array}$ & Bor + Mapatumumab & \\
\hline
\end{tabular}


Table 2. Cont.

\begin{tabular}{|c|c|c|c|c|c|c|c|c|}
\hline $\begin{array}{l}\text { Author, Year, Study } \\
\text { Design }\end{array}$ & No of Patients & Antibody & Target & $\begin{array}{l}\text { Median Prior } \\
\text { Therapies }\end{array}$ & Dose & No. of Cycles & Regimen & Outcome \\
\hline $\begin{array}{l}\text { Channan, 2010, Phase I, } \\
\text { Blood. }\end{array}$ & 37 & $\begin{array}{l}\text { Lorvotuzumab } \\
\text { mertansine } \\
\text { (ADC) (IgG1) }\end{array}$ & CD56 & 6 & $40-140 \mathrm{mg} / \mathrm{m}^{2} \times \mathrm{wk}$ & NR & $\begin{array}{l}\text { Lorvotuzumab mertansine } \\
\text { Monotherapy }\end{array}$ & $\mathrm{SD}=41 \%$ \\
\hline $\begin{array}{l}\text { Berdeja. 2012, Phase I, } \\
\text { JCO. }\end{array}$ & 44 (39REP) & $\begin{array}{l}\text { Lorvotuzumab } \\
\text { mertansine } \\
\text { (IgG1) }\end{array}$ & CD56 & $2(1-11)$ & $75-112 \mathrm{mg} / \mathrm{m}^{2}$ & NR & $\begin{array}{l}\text { LM + LEN (20mg) + Dex } \\
(40 m g)\end{array}$ & $\begin{array}{l}\mathrm{ORR}=59 \%, \mathrm{sCR} n=1, \mathrm{CR} \\
n=1, \mathrm{VGPR} n=8, \mathrm{PR} n=9\end{array}$ \\
\hline $\begin{array}{l}\text { Heffner, 2012, Phase } \\
\text { I/IIa, Blood. }\end{array}$ & 29/23 (REP) & $\begin{array}{l}\text { Indatuximab } \\
\text { Ravtansine } \\
\text { (ADC) (IgG1) }\end{array}$ & CD138 & $2(1-11)$ & $40-160 \mathrm{mg} / \mathrm{m}^{2}$ & NR & Indatuximab Monotherapy & $\begin{array}{l}\mathrm{PR}=1, \mathrm{SD}=11 \\
\mathrm{mPFS}=112 \text { days }(90-245)\end{array}$ \\
\hline $\begin{array}{l}\text { Kelly K. R., 2014, } \\
\text { PhaseI/IIa, Blood. }\end{array}$ & 45/36 (REP) & $\begin{array}{l}\text { Indatuximab } \\
\text { Ravtansine } \\
\text { (ADC) (IgG1) }\end{array}$ & CD138 & 3 & $80,100,120 \mathrm{mg} / \mathrm{m}^{2}$ & NR & Indatuximab + dex + Len & $\begin{array}{l}\mathrm{ORR}=78 \%, \mathrm{SCR}=1, \mathrm{CR}=2, \\
\mathrm{VGPR}=10, \mathrm{PR}=15, \mathrm{SD}=2\end{array}$ \\
\hline \multirow[t]{2}{*}{$\begin{array}{l}\text { Kelly K. R., 2016, } \\
\text { PhaseI/IIa, Blood. }\end{array}$} & 47/43 (REP) & $\begin{array}{l}\text { Indatuximab } \\
\text { Ravtansine }\end{array}$ & \multirow[t]{2}{*}{ CD138 } & $1-6$ & \multirow[t]{2}{*}{$80-100 \mathrm{mg} / \mathrm{m}^{2}$} & NR & Indatuximab + dex + Len & $\begin{array}{l}\mathrm{ORR}=78 \%, \mathrm{PR}=33 / 47, \mathrm{mPFS} \\
16.4 \mathrm{~m}\end{array}$ \\
\hline & 17 & $(\mathrm{ADC})(\mathrm{IgG1})$ & & $>2$ & & NR & $\begin{array}{l}\text { Indatuximab + dex + } \\
\text { Pomalidomide }\end{array}$ & $\mathrm{ORR}=79 \%, \mathrm{VGPR}=4, \mathrm{PR}=7$ \\
\hline
\end{tabular}

Abbreviations: REP; Response evaluable patients, mAb; Monoclonal Antibodies, ADC; Antibody Drug Conjugate, BAFF; B cell activating factor, len; Lenalidomide, Dex; dexamethasone, Bor, Bortezomib, Tab; Tabalumab, pom; Pomalidomide, pem; pembrolizumab, m; months, ORR; Objective response rate, CR; Complete response, PR: partial response, VGPR; Very good partial response, MR; Minimal response, PD; Progressive disease, NE; Not evaluable, mPFS; median Progression free survival, sCR; stringent complete response, SD; Stable disease, NR; Not reported, wk; weeks, LM; Lorvotuzumab mertansine, NEJM; New England Journal of Medicine, ASH; American Society of Hematology, JCO; Journal of Clinical Oncology. 
Table 3. Adverse effects of monoclonal Antibodies drugs.

\begin{tabular}{|c|c|c|c|}
\hline Author, Year, Study Design & Antibody & Adverse Effects $\geq$ Grade III & Common Adverse Effects \\
\hline Hansson,2015, Phase I & BI-505 & $\begin{array}{l}\text { Headache }(n=4) \text {, Pyrexia }(n=3) \text {, Infusion related reactions } \\
(n=1) \text {, Fluid overload }(n=1) \text {, T-wave inversion }(n=1) .\end{array}$ & $\begin{array}{l}\text { Fatigue (47\%), Pyrexia (32\%), Headache (32\%), } \\
\text { Nausea ( } 29 \%) \text {, Chills ( } 24 \%)\end{array}$ \\
\hline Callander, 2009 & Bevacizumab & $\operatorname{DVT}(n=3), \operatorname{SOB}(n=2)$, A fib $(n=3)$ & Fatigue \\
\hline Somlo, 2011, Phase II & Bevacizumab \pm Thalidomide & $\begin{array}{c}\text { Fatigue (16.6\%), HTN }(16.6 \%), \text { Neutropenia }(16.6 \%) \text {, } \\
\text { Hyponatremia }(16.6 \%) \\
\text { Lymphopenia }(16.6 \%) \text {, Fatigue }(16.6 \%), \text { Pulmonary HTN } \\
(16.6 \%)\end{array}$ & NR \\
\hline White, 2013, Phase II & $\begin{array}{l}\text { Bevacizumab + Bortezomib } \\
\text { Bortezomib + Placebo }\end{array}$ & $\begin{array}{c}\text { Thrombocytopenia (28\%), Neutropenia }(18 \%) \\
\text { Thrombocytopenia }(30 \%) \text {, Diarrhea }(10 \%)\end{array}$ & $\begin{array}{l}\text { Anemia, Diarrhea, Fatigue, URTI, Neuralgia } \\
\text { Anemia, Diarrhea, Fatigue, URTI, Neuralgia }\end{array}$ \\
\hline Rasche, 2015, Phase I & PAT-SM6 & Neutropenia (8.3), Back pain (8.3), bile duct stone (8.3) & Neutropenia (50), Leukopenia (67) \\
\hline Orlowski, 2015, Phase II & $\begin{array}{l}\text { Siltuximab + Bortezomib } \\
\text { Bortezomib + Placebo }\end{array}$ & $\begin{array}{l}\text { Neutropenia }(49 \%), \text { Thrombocytopenia }(48 \%) \\
\text { Neutropenia }(24 \%) \text { Thrombocytopenia }(34 \%)\end{array}$ & $\begin{array}{l}\text { Infections }(62 \%) \text {, Sensory neuropathy }(49 \%) \\
\text { Infections }(49 \%) \text { Sensory neuropathy }(51 \%)\end{array}$ \\
\hline Agura, 2009, Phase 1b & Dacetuzumab & Herpes Zoster, Renal failure & $\begin{array}{c}\text { Infusion reactions, grade (I/II), Fatigue }(47 \%) \text {, Neutropenia } \\
(28 \%) \text {, Thrombocytopenia }(25 \%) \text {, Diarrea }(22 \%), \\
\text { Constipation }(19 \%) \text {, Headache }(19 \%)\end{array}$ \\
\hline Husein, 2010, Phase I & Dacetuzumab & $\begin{array}{c}\text { Total grade } 3 \mathrm{AE}=30 \% \text {, Thrombocytopenia }(7 \%) \text {, Aseptic } \\
\text { meningitis }(5 \%) \text {, Renal failure }(5 \%)\end{array}$ & $\begin{array}{c}\text { Fatigue }(57 \%) \text {, headache }(43 \%) \text {, nausea }(23 \%) \text {, anemia }(21 \%) \text {. } \\
\text { Elevated LFTs }(41 \%) \text {, anorexia, back pain, constipation, } \\
\text { diarrhea, ocular hyperemia }(21 \%)\end{array}$ \\
\hline Bensinger, 2012, Phase I & Lucatumumab & $\begin{array}{c}\text { Thrombocytopenia (4\%), Increased LFTs }(4 \%) \text {, Increased } \\
\text { Lipase }(4 \%)\end{array}$ & $\begin{array}{c}\text { Infusion reactions, Anemia (7\%), Hypercalcemia (7\%), } \\
\text { Pyrexia (7\%) }\end{array}$ \\
\hline Martin, 2014, Phase I & Isatuximab (SAR650984) & Pneumonia, Fever, Hyperglycemia, Hypophosphatemia, & $\begin{array}{c}\text { Pneumonia 9\%, fever (3\%), apnea (3\%), fatigue (3\%), } \\
\text { hyperglycemia (3\%) }\end{array}$ \\
\hline Richter, 2016, Phase II & Isatuximab SAR650984 & NR & $\begin{array}{c}\text { Nausea (33\%), Fatigue (30\%), Dyspnea (26\%), Infusion } \\
\text { related } 49 \%\end{array}$ \\
\hline Martin. Phase Ib, 2017 & Isatuximab + Len + Dex & $\begin{array}{c}\text { pneumonia }(9 \%) \text {, fatigue }(7 \%) \text {. Hypokalemia, anaphylaxis, } \\
\text { febrile neutropenia ( } 5 \% \text { each). }\end{array}$ & $\begin{array}{c}\text { Thrombocytopenia (38\%), anemia (25\%), Neutropenia } \\
(60 \%)\end{array}$ \\
\hline Martin, 2014, Phase Ib & Isatuximab + Len + Dex & No DLT reported, IAR (6\%) & $\begin{array}{c}\text { Fatigue (41.9\%), Nausea (38.7), URTI(38.7\%), } \\
\text { Diarrhea(35.5\%) }\end{array}$ \\
\hline Voorhesse, 2009, Phase II & $\begin{array}{c}\text { Siltuximab } \\
\text { Siltuximab + Dexamethasone }\end{array}$ & $\begin{array}{l}\text { Thrombocytopenia, anemia, Neutropenia, abnormal LFTs, } \\
\text { fatigue. }\end{array}$ & $\begin{array}{c}\text { Diarrhea (29\%), Nausea (22\%), Constipation (20\%), Fatigue } \\
(43 \%) \text { Peripheral edema }(29 \%)\end{array}$ \\
\hline Suzuki, 2015, Phase I & Siltuximab & No DLT, Lymphopenia (89\%), Neutropenia (44\%) & Abnormal LFTs (44\%), Rash (44\%), Hyperlipidemia (44\%) \\
\hline Rossi,2009, Phase I & Atacicept & Neuropathy, Epiploic appendicitis. & $\begin{array}{c}\text { Infections, Bone Pains } \\
\text { Thrombocytopenia }(81.3 \%) \text {. Lvmphopenia }(43.8 \%)\end{array}$ \\
\hline Shinsuke Iida, 2016, Phase I & Tabalumab & Febrile Neutropenia, Tumor lysis syndrome, Ileus. & $\begin{array}{l}\text { Thrombocytopena (81.3\%), Lymphopenia }(43.8 \%) \text {, } \\
\text { Increased alanine aminotransferase }(43.8 \%)\end{array}$ \\
\hline Reje, 2017, Phase II & $\begin{array}{l}\text { Tabalumab } \\
\text { Placebo }\end{array}$ & Thrombocytopenia (12 8\%), Pneumonia (9.1\%) & $\begin{array}{c}\text { Thrombocytopenia ( } 37 \%) \text {, Fatigue (37\%), Diarrhea (35\%), } \\
\text { Constipation (32\%) }\end{array}$ \\
\hline Lesokhin, 2016, Phase Ib & Nivolumab & Pneumonitis (4\%), Myositis (4\%), Raised CPK (4\%) & seen in $52 \%$ patients \\
\hline Badros, 2017, Phase II & Pembrolizumab & $\begin{array}{c}\text { Hematologic }(40 \%) \text {, Hyperglycemia (25\%), pneumonia } \\
(15 \%)\end{array}$ & Pancytopenia (13\%), Hypothyroidism (10\%) \\
\hline Efebera, 2015, Phase I/II & Pidilizumab & Anemia $25 \%$, neutropenia $23 \%$, thrombocytopenia $34 \%$ & Fatigue $(50 \%)$, anorexia $(17 \%)$, hypophosphatemia $(17 \%)$ \\
\hline
\end{tabular}


Table 3. Cont

\begin{tabular}{|c|c|c|c|}
\hline Author, Year, Study Design & Antibody & Adverse Effects $\geq$ Grade III & Common Adverse Effects \\
\hline Channan, 2010, Phase I & Lorvotuzumab mertansine & Peripheral neuropathy, Fatigue, Acute renal failure & Fatigue, peripheral neuropathy, Headache, Raised AST \\
\hline Berdeja, 2012, Phase I & Lorvotuzumab mertansine & $\begin{array}{c}\text { Peripheral neuropathy, Neutropenia } n=1 \text {, Hyperuricemia } \\
\text { Tumor lysis syndrome } n=2\end{array}$ & Peripheral neuropathy $(42 \%)$ \\
\hline Heffner, 2012, Phase I/IIa & Indatuximab Ravtansine (ADC) & $\begin{array}{c}\text { Palmar-planter eryhtrodysesthesia syndrome }(N=1) \text {, } \\
\text { Elevated LFTs }\end{array}$ & Fatigue, Anemia, Diarrhea \\
\hline Kelly, 2014, Phasel/IIa & Indatuximab Ravtansine (ADC) & Mucosal inflammation $(n=1)$, Anemia $(n=1)$ & Fatigue, Hypokalemia, Diarrhea \\
\hline Kelly, 2016, PhaseI/IIa & Indatuximab Ravtansine (ADC) & NR & Diarrhea, Fatigue, Nausea \\
\hline Benson, 2015, phase I & IPH 2101 & leucopenia $n=1$, neutropenia $n=1$ & Myelodysplasia $n=1$, neutropenia, IRR \\
\hline Benson, 2012, Phase I & IPH 2101 & NR & Fatigue $n=10$, Chills $n=5$, pyrexia $n=5$ \\
\hline Kaufman,2013, Phase I & Milatuzumab & Anemia $20 \%$, CRS $4 \%$, Hypokalemia $4 \%$, Epistaxis $4 \%$ & $\begin{array}{c}\text { Nausea }(48 \%) \text {, Fever }(36 \%), \text { CRS }(20 \%) \text {, Headache }(20 \%) \text {, } \\
\text { HTN }(20 \%)\end{array}$ \\
\hline Lacy, 2008, Phase I & Figitumumab (CP 751,871) & Anemia (2.1\%), Hyperglycemia (2.1\%) & Anemia $(6.4 \%)$, Increased AST $(6.4 \%)$ \\
\hline Lacy, 2008, Phase I & Figitumumab (CP 751,871) & Muscle weakness (3.7\%), Increased AST (3.7\%) & Anemia $(7.4 \%)$, Increased ALT $(11 \%)$ \\
\hline Moreau,2011, Phase I & AVE1642 & Grade III hyperglycemia $n=1$ & $\mathrm{NR}$ \\
\hline Moreau,2011, Phase I & AVE1642 & Hypercalcemia $n=1$, renal vein thrombosis $n=1$ & NR \\
\hline Miguel, 2014, Phase II & VMP + Placebo & $\begin{array}{c}\text { All }=81 \%, \text { Neutropenia }(43 \%), \text { Thrombocytopenia }(25 \%), \\
\text { Pneumonia }(17 \%), \text { Median PFS }=17 \mathrm{~m}\end{array}$ & Infections (17\%), GI disorders $(11 \%)$ \\
\hline \multirow[t]{2}{*}{ Miguel, 2014, Phase II } & Siltuximab + VMP & $\begin{array}{c}\text { All }=92 \%, \text { Neutropenia }(62 \%), \text { Thrombocytopenia }(44 \%), \\
\text { Pneumonia }(17 \%), \text { Median PFS }=17 \mathrm{~m}\end{array}$ & Infections (29\%), GI disorders (11.5\%) \\
\hline & Siltuximab & Pneumonia, Thrombocytopenia & $\begin{array}{c}\text { Fatigue (63.6\%), Constipation (54.5\%), Paresthesia (45.5\%), } \\
\text { Myalgia (56.4\%) }\end{array}$ \\
\hline Baz, 2007, Phase II & Rituximab + MP & $\begin{array}{c}\text { Diarrhea (31\%), Neutropenia (51\%), Anemia (47\%), } \\
\text { Thrombocytopenia (40\%) }\end{array}$ & $\begin{array}{l}\text { Fever, fatigue, cough, dyspnea, diarrhea, nausea, diarrhea } \\
\text { and constipation. Possible AE related to rituximab were } \\
\text { IRR (11\%) }\end{array}$ \\
\hline \multirow[t]{2}{*}{ Vorhees, 2013, Phase II } & Siltuximab & Thrombocytopenia 28\%, Anemia 43\%, Neutropenia $7 \%$ & $\begin{array}{c}\text { Neutropenia 29\%, Anemia 35\%, Thrombocytopenia } 49 \% \text {, } \\
\text { Fatigue } 43 \% \text {, Abnormal Hepatic Function 31\%, Diarrhea } \\
29 \% \text {, Edema 29\%, Dyspnea 27\%, Dizziness 25\%, Nausea } \\
28 \% \text {, Insomnia 28\%, Weight increase } 20 \%\end{array}$ \\
\hline & Siltuximab + Dexa & $\begin{array}{c}\text { Thrombocytopenia } 26 \% \text {, Anemia } 16 \% \text {, Neutropenia } 18 \% \text {, } \\
\text { Fatigue } 8 \%\end{array}$ & $\mathrm{NR}$ \\
\hline Ribrag, 2017, Phase I & Pembrolizumab & r & $\begin{array}{c}\text { Asthenia } 17 \% \text {, Pruritus } 3 \% \text {, Arthralgia 3\%, Fatigue 3\%, } \\
\text { Hyperglycemia 3\%, Blurred vision 3\%, Aspartate } \\
\text { Aminotransferase increased } 3 \%\end{array}$ \\
\hline Rasche, 2015, Phase I & PAT-SM6 & Neutropenia $8 \%$ & $\begin{array}{c}\text { Neutropenia } 50 \% \text {, Leukopenia } 66 \% \text {, Increase in C reactive } \\
\text { protein } 8 \% \text {, Hypertriglyceridemia } 8 \%\end{array}$ \\
\hline Raje, 2016, Phase I & Tabalumab & $\begin{array}{c}\text { Peripheral Sensory Neuropathy } 15 \% \text {, Fatigue } 6 \% \text {, Diarrhea } \\
8 \% \text { m Thrombocytopenia } 31 \% \text { m Anemia } 6 \% \text {, Neutropenia } \\
15 \% \text {, Pneumonia } 13 \% \text {, Hypokalemia } 8 \% \text {, Renal Failure } 8 \% \text {, } \\
\text { Gi Hemorrhage } 4 \% \text {, Musculoskeletal pain } 6 \%\end{array}$ & $\begin{array}{l}\text { Peripheral Sensory Neuropathy } 63 \% \text {, Fatigue } 58 \% \text { m } \\
\text { Diarrhea } 54 \% \text {, Nausea } 48 \% \text {, Thrombocytopenia } 33 \% \text {, } \\
\text { Anemia } 23 \% \text {, }\end{array}$ \\
\hline
\end{tabular}


Table 3. Cont.

\begin{tabular}{|c|c|c|c|}
\hline Author, Year, Study Design & Antibody & Adverse Effects $\geq$ Grade III & Common Adverse Effects \\
\hline Raab, 2016, Phase I/IIa & MOR 202 & NR & IRRs $10 \%$ \\
\hline Patnaik, 2014, Phase I & Ficlatuzumab & Hyper/Hypokalemia, Diarrhea, Fatigue & Peripheral edema, fatigue, nausea \\
\hline \multirow[t]{2}{*}{ Orlowski, 2015, Phase II } & Siltuximab + placebo & $\begin{array}{c}\text { AE grade }>3: 74 \% \text {. Neutropenia } 29 \% \text {, Thrombocytopenia } \\
34 \% \text {, Bleeding events }<2 \% \text {, Infections } 14 \%\end{array}$ & $\begin{array}{c}\text { Neutropenia } 36 \% \text {, Thrombocytopenia } 45 \% \text {, Peripheral } \\
\text { Sensory Neuropathy } 51 \% \text {, Diarrhea } 35 \% \text {, Anemia } 29 \% \text {, } \\
\text { Fatigue } 27 \% \text {, Infection } 49 \%\end{array}$ \\
\hline & Siltuximab + Bortezomib & $\begin{array}{c}\text { AE grade }>3: 91 \% \text {. Neutropenia } 49 \% \text {, Thrombocytopenia } \\
48 \% \text {, Bleeding events }<2 \% \text {, infection } 16 \%\end{array}$ & $\begin{array}{c}\text { Neutropenia } 59 \% \text {, Thrombocytopenia } 57 \% \text {, Peripheral } \\
\text { Sensory Neuropathy } 49 \% \text {, Diarrhea } 35=6 \% \text {, Anemia } 31 \% \text {, } \\
\text { Fatigue } 27 \% \text {, Infection } 62 \%\end{array}$ \\
\hline Mikhael, 2017, Phase IB & $\begin{array}{l}\text { Isatuximab + Dexa } \\
\text { Pomalidomide }\end{array}$ & Neutropenia $92 \%$, Thrombocytopenia $32 \%$ & Fatigue $62 \%$, Diarrhea 35\%, Dyspnea 31\% \\
\hline Martin, 2017, Phase IB & $\begin{array}{c}\text { Isatuximab }+ \text { Lenalidomide }+ \\
\text { Dexa }\end{array}$ & $\begin{array}{c}\text { Anemia } 25 \% \text {, Lymphopenia 58\%, Neutropenia } 60 \% \text {, } \\
\text { Leukopenia 53\%, Thrombocytopenia 38\%, Fatigue 7\%, } \\
\text { Pneumonia 9\%, Febrile Neutropenia 5\%, Anaphylactic } \\
\text { Reaction 5\%, Hypokalemia 5\% }\end{array}$ & $\begin{array}{c}\text { Anemia } 98 \% \text {, Lymphopenia } 95 \% \text {, Neutropenia } 89 \% \text {, } \\
\text { Leukopenia } 91 \% \text {, Thrombocytopenia } 91 \% \text {, IARs } 56 \% \text {, } \\
\text { Diarrhea } 53 \% \text {, Fatigue } 49 \% \text {, URTI } 40 \% \text {, Nausea } 35 \% \text {, } \\
\text { Insomnia } 32 \% \text {, Cough } 26 \% \text {, Headache } 23 \% \text {, Muscle spasm } \\
23 \% \text {, Vomiting } 23 \%\end{array}$ \\
\hline Lida, 2016, Phase I & Tabalumab + Bortezomib + Dexa & >Grade3 AE: $81.3 \%$ & $\begin{array}{c}\text { Thrombocytopenia } 81 \% \text {, Lymphopenia } 43 \% \text {, Anemia } 31 \% \text {, } \\
\text { Increase Alanine Aminotransferase } 43 \% \text {, GI disturbances } \\
62 \% \text {, Constipation } 38 \%\end{array}$ \\
\hline Lendvai, 2016, Phase Ib & Isatuximab + Dexa Lenalidomide & NR & $\begin{array}{l}\text { IARs } 65 \% \text {, Fatigue } 46 \% \text {, Pyrexia } 35 \% \text {, Diarrhea } 31 \% \\
\text { Thrombocytopenia } 100 \% \text {, Neutropenia } 93 \% \text {, Asthenia } 7 \% \text {, }\end{array}$ \\
\hline Fouquet, 2018, Phase I & F50067 + Dexa Lenalidomide & Thrombocytopenia $64 \%$, Neutropenia 57\%, Anemia $14 \%$ & $\begin{array}{c}\text { Thrombocytopenia } 100 \% \text {, Neutropenia } 93 \% \text {, Asthenia } 7 \% \text {, } \\
\text { Hyperhidrosis } 7 \% \text {, Pyrexia } 7 \% \text {, Dyspnea } 7 \% \text {, Pulmonary } \\
\text { Embolism 7\%, Femoral Neck Fracture 7\%, Rectal } \\
\text { hemorrhage } 7 \%\end{array}$ \\
\hline \multirow[t]{2}{*}{ Brighton, 2017, Phase II } & Siltuximab & NR & $\begin{array}{c}\text { Infections and Infestations 38\%, Renal and Urinary } \\
\text { Disorders 7\% }\end{array}$ \\
\hline & Placebo & 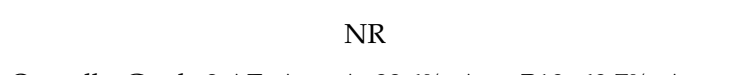 & $\begin{array}{c}\text { Infections and Infestations 33\%, Renal and Urinary } \\
\text { Disorders } 16 \%\end{array}$ \\
\hline Belch, 2011, Phase II & Bortezomib +/- Mapatumumab & $\begin{array}{c}\text { Overall > Grade } 3 \text { AE. Arm A: } 88.6 \% \text {, Arm B10: } 69.7 \% \text {, Arm } \\
\text { B20: } 61 \%\end{array}$ & Hematological, Peripheral Sensory Neuropathy \\
\hline Badros, 2016 & $\begin{array}{c}\text { Pembrolizumab + Pomalidomide } \\
\text { + Dexa }\end{array}$ & $\begin{array}{c}\text { Anemia } 21 \% \text {, Neutropenia } 40 \% \text {, Lymphopenia } 15 \% \text {, } \\
\text { Thrombocytopenia } 8 \% \text {, Fatigue } 15 \% \text {, Hyperglycemia } 25 \% \text {, } \\
\text { URI } 25 \% \text {, Rash } 10 \%\end{array}$ & $\begin{array}{c}\text { Dyspnea } 54 \% \text {, Dizziness } 44 \% \text {, Increased Creatinine } 38 \% \text {, } \\
\text { Edema } 35 \% \text {, Rash } 30 \% \text {, Interstitial Pneumonitis } 13 \% \text {, } \\
\text { Hypothyroidism } 10 \%\end{array}$ \\
\hline Ansell, 2016, Phase I & Nivolumab + Ipilimumab & NR & NR \\
\hline
\end{tabular}

Abbreviations: ADC; Antibody drug conjugate, VMP; Bortezomib melphalan prednisone, MP; Melphalan prednisone, GI; Gastrointestinal, CRS: Complement release syndrome, IRR; Infusion related reactions, DLT; Dose limiting toxicity, PFS: Progression free survival, NR: not reported, Dexa; dexamethasone. 


\subsection{Surface Receptor-Targeting Antibodies}

\subsubsection{CD38}

CD38 is highly expressed in MM cells. It plays a key role in the growth of cells and their survival. CD38 acts as a surface receptor to regulate the proliferation of T-cells by means of cytokine recruitment and cell adhesion. It also acts as an ectoenzyme in the synthesis of cyclic adenosine diphosphate ribose (cADPR) and the hydrolysis of cADPR to ADPR and generates NAADP from NADP. NAADP, CADPR and ADPR play important roles in the regulation of calcium influx and other cellular signaling pathways [18,19]. Isatuximab is anti-CD38 $\mathrm{mAb}$ that produces its anticancer effects by means of CDC, ADCC or direct toxicity. Isatuximab as monotherapy achieved an ORR of $32 \%$ and $24 \%$ in patients who had failed 6 and 5 lines of therapy, respectively $[20,21]$. When isatuximab was combined with lenalidomide and dexamethasone in doses of 3,5 or $10 \mathrm{mg} / \mathrm{kg}$, it produced an ORR of $64.5 \%$ and $56 \%$ in patients with 6 and 5 prior lines of therapies respectively [22,23]. The use of isatuximab $+\mathrm{Rd}$ in doses of $10 \mathrm{mg} / \mathrm{kg}$ and $20 \mathrm{mg} / \mathrm{kg}$ achieved a similar ORR of $50 \%$ with a clinical benefit response (CBR) significantly higher at $83 \%$ with a $10 \mathrm{mg} / \mathrm{kg}$ dose as compared with CBR of $50 \%$ with a $20 \mathrm{mg} / \mathrm{kg}$ dose [24]. Mikhael et al. studied isatuximab in combination with pomalidomide and dexamethasone in patients with 4 prior lines of therapy and achieved the highest PR of $62 \%$. In that study, 1 patient achieved CR and 8 patients achieved very good partial response (VGPR) with clinical benefit response (CBR) of $73 \%$ [25]. Patients tolerated Isatuximab at $10 \mathrm{mg} / \mathrm{kg}$ dosing while $20 \mathrm{mg} / \mathrm{kg}$ caused adverse events such as pneumonia, fatigue, hypokalemia, anaphylaxis and febrile neutropenia. A randomized phase III trial to compare isatuximab + Pd versus Pd is currently ongoing [26]. MOR202 is another anti-CD38 antibody under investigation as a single agent and in combination with lenalidomide and pomalidomide separately. Investigators saw long lasting tumor control with MOR202 monotherapy with patients achieving 19\% PR and 13\% VGPR, MOR202 + lenalidomide resulted in 5 out of 7 patients achieving PR and MOR202 + pomalidomide resulted in achieving CR in 2 out of 5 patients [27].

\subsubsection{CD40}

CD40 is a surface receptor that is highly expressed on cells with increased potential for proliferation. It has been detected in various B-cell neoplasms including MM [28]. Dacetuzumab is an anti-CD40 mAb that is being tested both as single and combination therapy. The use of Dacetuzumab as monotherapy in 44 RRMM patients with prior 5 lines of therapy achieved no ORR with 20\% patients in SD [29]. The use of Dacetuzumab + Rd in 36 RRMM with prior 4 lines of therapy produced OR of 39\% with PR of 33\% [30]. Lucatumumab is another anti-CD40 mAb with two distinct anti-tumor activities; it stops CD40-CD40L dependent cell growth and causes tumor cell lysis by ADCC [31]. The use of Lucatumumab as monotherapy in 28 patients who relapsed to 3 lines of therapy achieved PR in one patient and $43 \%$ of patients achieved SD [31].

\subsubsection{KIR}

Killer-cell immunoglobulin like receptors (KIR) are transmembrane glycoproteins that express on the surface of nature killer (NK) cells. KIRs are mostly inhibitory as they decrease the cytotoxic potential of NK cells. NK-cells play an important role in protection against cancer development. IPH-2101 is an anti-KIR mAb that enhances the cytotoxic potential of NK cells against cancer cells by ADCC. IPH-2101 did not produce any ORR when used as monotherapy in RRMM [32]. Even in phase I-II trials, IPH-2101 used as monotherapy in smoldering MM did not achieve a clinical response [33]. When IPH-2101 was used in combination therapy with lenalidomide in the phase-I trial, ORR of 33.3\% $(n=5)$ was achieved with two VGPR and three PR while six patients had SD. IPH-2101 in a dose range of $0.2-2 \mathrm{mg} / \mathrm{kg}$ was also well tolerated [34]. 


\subsubsection{CD74}

CD74 is a membrane glycoprotein found on B-cells, MM cells and monocytes. Because of its rapid internalization, association with major histocompatibility complex class II and restricted expression by normal cells, CD74 can deliver cytotoxic drugs inside cancer cells [35]. These properties led to a phase I clinical trial of anti-CD74 humanized mAb, milatuzumab for treating RRMM patients. $25 \mathrm{MM}$ patients who relapsed after 5 prior lines of therapies were treated with milatuzumab and no ORR was achieved. Out of 19 patients who completed treatment, five had SD for 3 months after therapy while one had SD for 17 months. CRS was seen in five patients [36]. There is a need for further trials using milatuzumab with combination chemotherapy.

\subsubsection{ICAM-1 (CD54)}

Intercellular adhesion molecule (ICAM-1) helps in the adhesion of MM cells to marrow stromal cells with resultant tumor proliferation. The ICAM-1 overexpression is associated with resistance to chemotherapy resulting in advanced disease [37,38]. Targeting ICAM-1 by humanized IgG1 mAb BI-505 as monotherapy in 35 RRMM patients did not achieve an ORR with $24 \%$ patients having SD and $65 \%$ having PD [39].

\subsubsection{Insulin Like Growth Factor-1 (IGF-1)}

IGF-1 receptor and binding proteins play a critical part in MM pathogenesis by up regulating proliferation, angiogenesis, tumor survival and osteolysis by stimulating osteoclast activity. IGF-1 attracts MM cells to bone marrow, up regulates expression of anti-apoptotic molecules and down regulates pro-apoptotic molecules hence stimulating proliferation of MM cells. The expression of IGF-1 in MM is associated with poor outcomes and causes resistance to therapy [40]. In phase I trials, investigators have tested AVE1642 and figitumumab (Anti-IGF-1R mAb) as monotherapy versus combination with bortezomib or dexamethasone. The use of figitumumab as monotherapy achieved no ORR while its combination with dexamethasone achieved PR in 6 out of 27 patients [41]. When AVE1642 was used as monotherapy, it produced MR in 1 patient while maintaining SD in 7 out of 17 patients. AVE1642 + dexamethasone produced CR and PD in one patient each while SD in 3 out of 11 patients [42]. Despite favorable safety as both monotherapy and in combination, investigators did not consider the response as significant.

\subsubsection{GRP78}

Glucose regulated protein 78 (GRP78) is a cellular protein that is found mostly in the endoplasmic reticulum (ER) and mitochondria and helps in protein assembly and controls ER stress signaling. GRP78 is an anti-apoptotic protein and can translocate to cytosol and the cell surface in tumor cells where it plays a role in angiogenesis, tumor progression and metastasis. It also results in resistance to proteasome and BRAF inhibitors [43]. PAT-SM6 targets GRP-78 and causes cytotoxicity in MM cells by inducing apoptosis and CDC [44]. Although PAT-SM6 was well tolerated in a phase I trial as a single agent in 12 RRMM patients with 4 lines of therapy it failed to produce OR with SD in $33.3 \%$ [44]. The favorable safety profile makes it a candidate for further trials with combination therapies [45].

\subsection{Non-Surface Receptor Targeting Antibodies}

\subsubsection{CXCR-4}

CXCR-4 is expressed in many hematological malignancies and is thought to have a role in cancer cell survival [46]. CXCR-4/SDF1 axis plays an important role in the localization of MM cells in bone marrow, regulation of MM cells trafficking by adhesion, invasion and mobilization of MM cells out of the bone marrow [47]. F50067 is a humanized IgG1 anti-CXCR-4 mAb and exerts its ant-tumor effects by decreasing the interaction of MM cells with bone marrow microenvironment and resultant 
toxicity through ADCC and CDC. Fouquet et al studied 14 RRMM patients as F50067 monotherapy and combination of F50067 + Rd (low-dose dexamethasone) with 66.7\% ORR ( $\geq$ PR) in combination cohort and $\mathrm{OR}$ of $33.3 \%$ ( $\geq \mathrm{SD}$ ). Investigators discontinued the study due to hematological toxicities [48].

\subsubsection{Interleukin 6 (IL 6)}

IL-6 is a cytokine that mediates B- and T-cell immune function. It is an important regulator of the inflammatory response and mediates differentiation and proliferation of plasma cells. Siltuximab is an anti-IL6 $\mathrm{mAb}$ that demonstrated potent activity against MM in preclinical studies in combination with bortezomib and dexamethasone $[49,50]$.

The Brighton et al. phase II randomized control trial (RCT) of siltuximab monotherapy versus placebo to evaluates whether siltuximab can delay the progression of high risk SMM to MM. One year PFS was $84.5 \%$ in siltuximab group versus $74.4 \%$ in the placebo group. This trial failed to meet the hypothesis that siltuximab can increase PFS by $14 \%$ [51]. Orlowski et al. did a phase II RCT of comparison of siltuximab + bortezomib versus bortezomib monotherapy. They demonstrated no significant difference in mean progression free survival (mPFS) (8 vs. 7.6 months), mOS (20.8 vs. 26.8 months), CR (11 vs. 7\%) and ORR of 55 versus $47 \%$ [52]. In another trial of siltuximab as monotherapy versus siltuximab and dexamethasone in patients who failed four previous lines of therapy, siltuximab monotherapy did not achieve OR with SD of $62 \%$ and PD of $39 \%$. In combination therapy, ORR of $23 \%$ was achieved with PFS of 3.7 months, SD $57 \%$ and PD 17\% [53]. Suzuki et al. evaluated siltuximab + Rd in 9 patients with 1-2 previous lines of therapy and reported CR in $22 \%$ and PR in $44 \%$ [54].

\subsubsection{Vascular Endothelial Growth Factor (VEGF)}

Angiogenesis plays a vital role in the growth and spread of neoplasms. MM can secrete VEGF, resulting in an increase in bone marrow micro-vascularity, which is an important prognostic factor in MM [55-57]. VEGF stimulates the endothelium of microvasculature and bone marrow stromal cells to secrete IL-6, which is also a strong growth factor for malignant MM cells [58]. Bevacizumab is a mAb, which binds VEGF and blocks its effects on angiogenesis and proliferation [59]. Callender et al. evaluated the role of bevacizumab $+\mathrm{Rd}$ in 31 patients who had failed prior median 3 lines of therapy and described OR of $70 \%$. The results were not considered superior to $\mathrm{Rd}$ alone where OR was 60\% [60]. In an RCT by Somlo et al. using bevacizumab alone versus bevacizumab \pm thalidomide in 6 patients each with prior median three lines of therapy, bevacizumab monotherapy did not achieve OR while the addition of thalidomide slightly improved the response with PR of 33\% [61]. In another RCT by White et al. for comparing bevacizumab + bortezomib in 49 patients versus bortezomib + placebo in 53 patients with 1-3 previous lines of therapy, there was no statistically significant difference in ORR (51\% vs. 43.3\%) [62].

\subsubsection{B-Cell Activating Factor (BAFF)}

BAFF and APRIL (a proliferation-inducing ligand) are members of the TNF- $\alpha$ family and are highly expressed in MM. Both targets activate phosphatidylinositol-3 (PI-3) kinase and mitogen activated protein kinase with resultant up regulation of MCL-1 and BCL-2 anti-apoptotic proteins in MM. They also protect MM cells from dexamethasone-induced apoptosis [63]. Their levels are also associated with disease severity [64]. Atacicept and tabalumab are anti-BAFF mAbs. Atacicept blocks soluble forms of BAFF and APRIL, while tabalumab blocks both soluble and membrane bound forms of BAFF [65]. Rossi et al. evaluated atacicept as monotherapy in 12 patients who had failed 5 prior lines of therapy and no OR was achieved [65]. Shinsuki et al. studied tabalumab in doses of 100-200 mg in combination with $\mathrm{Vd}$ in RRMM patients with 1-5 prior lines of therapy and reported a combined OR of $56.3 \%$ and tabalumab was well tolerated [66]. Raje et al. studied tabalumab $100 \mathrm{mg}, 300 \mathrm{mg}$ and placebo $+\mathrm{Vd}$ each and found no statistically significant difference between OR and PFS. They reported an ORR of $58.1 \%, 59.5 \%$ and $61.1 \%$ with tabalumab of $100 \mathrm{mg}, 300 \mathrm{mg}$ and placebo $+\mathrm{Vd}$ respectively [67]. RRMM patients who had low BAFF levels achieved a moderately long PFS, which points to its role as an important prognostic indicator in RRMM [67]. 


\subsubsection{TRAIL}

Tumor necrosis factor related apoptosis-inducing ligand (TRAIL/Apo2L) is a part of the TNF family and can induce programmed cell death of neoplastic cells while causing no toxicity against normal body tissues. TRAIL mediated apoptosis occurs following its binding to death receptors, TRAIL-R1 (DR4) and/or TRAIL-R2 (DR5). Mapatumumab is a humanized mAb that targets and triggers TRAILR1 receptor. The combination of mapatumumab with bortezomib showed promising results in preclinical studies that led to clinical studies of mapatumumab [68]. Belch et al. [69] studied mapatumumab in combination with bortezomib. They divided patients into three arms: Arm A bortezomib alone, Arm B10 - mapatumumab 10 mg/kg + bortezomib, Arm B20 - mapatumumab $20 \mathrm{mg} / \mathrm{kg}+$ bortezomib. They reported ORR of $51.4 \%, 30.3 \%$ and $52.8 \%$ while the median duration of response was 8.5, 9.3 and 7.6 months in arms A, B10 and B20, respectively. Although there was no significant toxicity, mapatumumab failed to achieve significant clinical improvement. These results do not favor further studies of mapatumumab + bortezomib in RRMM patients.

\subsection{Immune Checkpoint Inhibitors}

\section{PD-1/PD-L1}

Investigators saw PD-1 expression on the surface of T-cells and expression of its ligand PDL-1 on tumor cells. PD-1/PDL-1 interaction inhibits the proliferation of T-cells. PD-1 expression on plasma cells is increased in the presence of bone marrow stromal cells and is associated with advanced disease [70]. mAbs against PD-1/PD-L1 block the escape of tumor cells from the immune system by enhancing T-cell function [71]. Nivolumab, a mAb against PD-1, achieved CR and OR in only one patient out of 27 RRMM patients when it was used as monotherapy [72]. The use of nivolumab in combination with ipilimumab (CTLA4 $\mathrm{mAb}$ ) in 7 RRMM who failed 5 prior lines of therapy failed to achieve ORR and had results similar to nivolumab monotherapy [73]. Ribrag et al. studied pembrolizumab in 30 RRMM patients with $57 \%$ SD as the best response [74]. Pembrolizumab in combination with Pd were studies by Badros et al. in 48 patients who had 3 previous lines of therapy. Among 27 response evaluable patients, 4 had a stringent complete response (sCR), 3 had VGPR and 14 PR with mPFS of 17.4 months [75]. Investigators studied Pidilizumab that is another $\mathrm{mAb}$ against PD-1 in combination with lenalidomide. Only one patient achieved PR and VGPR was achieved by 3 patients out of 12 RRMM patients [76].

There have been many concerns regarding the safety of combination of mAbs targeting PD-1/PD-L1 with IMiDs. This is supported by data from KEYNOTE-183 [74] (pembrolizumab with pomalidomide and dexamethasone) and KEYNOTE- $185{ }^{95}$ (pembrolizumab with lenalidomide) trials that reported increased mortality, increased incidence of grade 3-5 adverse events in patients treated with pembrolizumab as compared to control group.

\subsection{Antibody Drug Conjugate (ADC)}

\subsubsection{CD56}

CD56 (neuronal cell adhesion molecule) is a cell surface glycoprotein that is particularly expressed on NK cells, neuronal cells and cytotoxic cells [77]. We generally do not see expression of CD56 on benign B-cells and it can be expressed on more than 70\% of MM cells [78]. Lorvotuzumab is anti-CD56 mAb that is conjugated to a maytansinoid cytotoxic agent known as DM-1 [79]. Channan et al. evaluated lorvotuzumab mertansine (LM) monotherapy in 37 patients with 6 previous lines of therapy and those patients did not achieve an OR [78]. Berdeja et al. evaluated LM in addition to Rd in 44 patients with median 2 previous lines of therapy. An ORR of 58\%, $1 \mathrm{sCR}$, CR each and 8 VGPR were reported in 32 response evaluable patients. Peripheral neuropathy was the most commonly found an adverse effect. Investigators felt that this toxicity could be explained by CD56 distribution on neuronal and NK cells [80]. 


\subsection{2. $\mathrm{CD} 138$}

CD138 (syndecan-1) is a heparan-sulfate coated glycoprotein that facilitates MM cell adhesion and its loss from the cell surface may lead to MM migration and metastasis [81]. It also functions as a co-receptor for MM growth receptors [82]. Indatuximab ravtansine (IR, BT-062) is the antibody drug conjugate of anti-CD138 chimerized mAb and cytotoxic maytansinoid DM4.

The binding of BT-062 and CD138 leads to CD138 internalization and release of anti-microtubule agent cytotoxic DM4 that that leads to MM cell death. Heffner et al. studied IR in 29 patients with medians of 2 previous lines of therapy as monotherapy and reported OR in one patient [83]. Kelly et al. evaluated IR $+R d$ in 64 patients with medians of 3 previous lines of therapy and reported an OR of $78 \%$. Later they did head to head trials of IR $+\mathrm{Rd}$ versus IR $+\mathrm{Pd}$. They reported no statistically significant difference in OR (78\% vs. $79 \%)$ [84].

\subsection{Future Prospective Therapies}

\subsubsection{Bi-Specific Antibodies (BiAb)}

Bi-specific antibodies are a novel approach in the treatment of MM. They have a unique potential to target two different antigens at the same time. These targets could be a cancer cell or these antibodies can target body's immune cells and cancer cells at the same time. They involve both adoptive cytolytic and innate immune cells simultaneously against cancer cells. There are different kinds of bi-specific antibodies (BiAb) like Bi-specific T-cell engaging antibody (BiTEs) and bi-specific antigen binding fragments (BiFabs), depending on targets. BiTEs bind tumor cells and immune cells by means of the interaction of CD3 with antigens on tumor cells (Figure 2). This interaction activates T-cells that attack the targeted tumor cells [85]. Various BiTEs that target BCMA and CD3 such as EM801, JNJ-64007957 and BI 836909 have shown favorable results in in vivo and in vitro models of MM [86,87]. Topp et al. studied AMG 420 (previously BI 836909) in 35 RRMM patients with $\geq 2$ prior lines of therapy. At dose of 400ug they reported ORR of 83\% (5/6) with 3 patients having MRD-negative CRs.

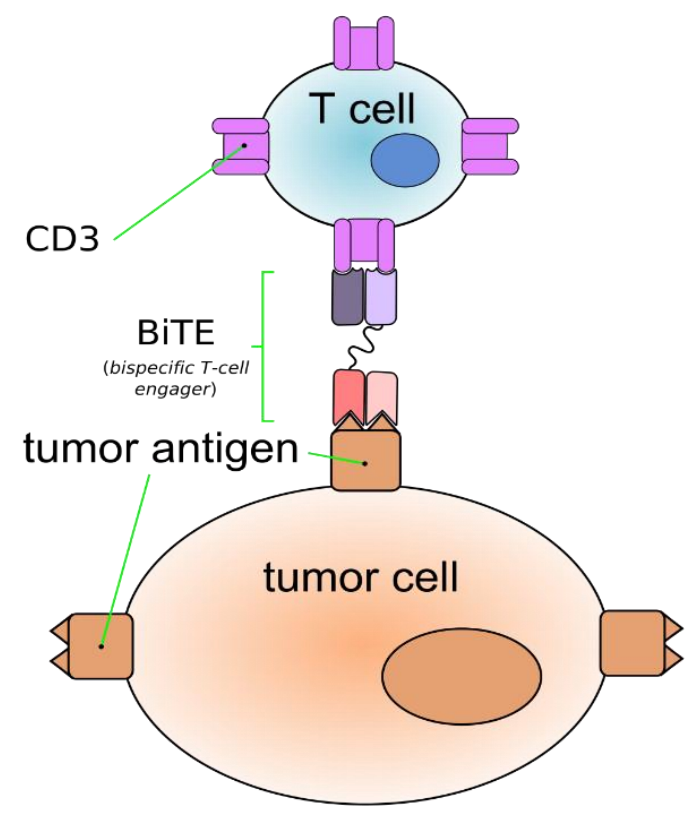

Figure 2. Bi-specific T-cell engaging antibody (BiTEs) bind tumor cells and immune cells through the interaction of $\mathrm{CD} 3$ with antigens on tumor cells.

Several clinical trials are currently ongoing to study BiTEs. PF-06863135 is an anti-CD3/anti-BCMA bispecific monoclonal antibody for MM patients (NCT03269136, NCT03145181, NCT03269136 and NCT02514239). There are a few other BiTEs in pre-clinical studies combining CD3 and CD138 that 
showed significant activity against MM in murine and in vitro models [88]. NKG2D is an activation receptor present on $\mathrm{CD}^{+} \mathrm{T}$-cells, NK cells, $\gamma \delta \mathrm{T}$-cells and NKT-cells. NKG2D and CS1 tumor related antigens represent a possible target by bi-specific antibodies. A bi-specific antibody targeting NKG2D and CS1 simultaneously has shown an enhanced killing of MM cells in vivo models [89]. There is another novel approach to treat MM using BiFabs that are bi-specific antibodies which target two distinct epitopes on the same antigen. Comparison of BiFabs targeting BCMA and CS1 demonstrated that BiFab-BCMA had greater anti-myeloma potential than BiFab-CS1. BiFab-BCMA specifically directs T-cells for MM cell lysis and produces results similar to CAR-T BCMA in vivo and in vitro studies [90]. Cytokine release syndrome is a form of cytokine storm that can happen as a dangerous complication of extreme T-cell activation.

\subsubsection{CD47}

TTI-622 is recombinant soluble fusion protein that is produced by linking sequences coding N-terminal CD47 binding domain of human SIRP $\alpha$ with Fc domain of IG4. TTI-622 binds human CD47 and prevents the delivery of inhibitory "do not eat" signal to macrophages. There is an ongoing phase $1 \mathrm{a} / 1 \mathrm{~b}$ trial of TTI-622 in the treatment of advanced relapsed or refractory multiple myeloma and lymphoma [91].

\section{Discussion}

An extensive review of the literature showed that isatuximab (anti-CD38) and F50067 (anti-CXCR4) were the only two mAbs that produced encouraging results as monotherapy with ORR of $66.7 \%$ and $32 \%$ respectively [32,92]. Isatuximab used in combination with $\mathrm{Rd}$ produced CBR of $83 \%$ and in combination with Pd produced CBR of 73\% [93,94]. However, the clinical trial of F50067 with both monotherapy and combination of $\mathrm{Rd}$ was discontinued due to significant hematological toxicities [32]. Our review also shows that trials using indatuximab, pembrolizumab, lorvotuzumab, siltuximab and dacetuzumab in combination therapy produced better outcomes as compared to monotherapies in RRMM.

Immune therapy has been of increasing interest as the immune system is significantly impaired with negative effects on both humoral and cellular immunity [16]. Antibody drug conjugates are an emerging treatment modality for MM because of their targeted nature. Indatuximab ravtansine could not produce favorable outcomes as a monotherapy [68] but produced an ORR 78\% and 79\% in combination with $\mathrm{Rd}$ and $\mathrm{Pd}$, respectively $[69,70]$. Similarly, Lorvotuzumab mertansine did not achieve an ORR as a monotherapy but achieved an ORR of 59\% in combination with Rd [64,65]. These results highlight the possibility of combination therapies being effective where original monotherapy was not. Another possible treatment strategy of immune checkpoint inhibitors couldn't show a beneficial effect in RRMM and was associated with prohibitive toxicities [70,95-97].

Investigators seeking future treatment recommendations should seek guidance from data produced in large well-designed randomized phase II-III trials, but they can formulate preliminary predictions. Due to the wavering escape strategies of myeloma cells, the role of precision medicine utilizing immunotherapies as a cornerstone in combination with approved therapies to treat MM is evolving [98]. It is challenging to target multiple evolving abnormalities at a precise time, in the right sequence and with the correct combination to prevent future relapses. This forms the basis of on-going trials evaluating 4 drug treatment strategies with or without a mAb compared to standard of care triple drug regimens [14].

Many questions remain unanswered, most relevant to immune therapy being the ideal timing of $\mathrm{mAb}$ in clinical course and the role of genomic profiling. It seems logical to use targeted immuno-modulation early in the disease when the immune system is more capable of responding but toxicities may be offset some of these approaches. Patient who cannot achieve consolidation with high dose melphalan and autologous transplant may benefit from earlier use of mAbs. Understanding and controlling the adverse effects associated with these drugs will also be important. 
Despite advances in understanding, different options are deployed in a relatively empiric fashion, relying on disease characteristics clinically rather on genotype, molecular features or mutations [99]. Receptor density studies [100], immuno-phenotyping and emerging understanding about molecular minimal residual disease (MRD) status may be of utility in deciding drugs for induction and maintenance therapy $[101,102]$ and aid in determining when to stop any drug treatment altogether based on MRD negativity in order to ultimately reduce the financial burden and clinical toxicity $[15,103]$. With further treatment insight about biological drivers, checkpoint inhibitors, tumor microenvironment and interaction with the tumor cells we can hope to approach the threshold of treatment by individualizing regimen for each patient.

Author Contributions: A.I., H.H. and F.A., contributed to the conception/design of the study. A.I., H.H. N.I., A.M., A.S., F.R. and S.S. contributed significantly to data collection, analysis, interpretation, drafted and revised the final manuscript. N.R., R.C., J.N.V., A.S.K. and F.A. participated in the critical revision of the article.

Funding: This study received no financial support.

Conflicts of Interest: F.A. has advisory board membership and participates in speakers' program of Seattle Genetics and Incyte Corporation. This membership had no role in the design of the study; in the collection, analyses, or interpretation of data; in the writing of the manuscript, or in the decision to publish the results. All other authors declare no potential conflict of interest.

\section{References}

1. NIH. Cancer Stat Facts: Myeloma. Available online: https://seer.cancer.gov/statfacts/html/mulmy.html. (accessed on 28 October 2018).

2. Pratt, G.; Goodyear, O.; Moss, P. Immunodeficiency and immunotherapy in multiple myeloma. Br. J. Haematol. 2007, 138, 563-579. [CrossRef] [PubMed]

3. Neri, P.; Bahlis, N.J. Genomic instability in multiple myeloma: Mechanisms and therapeutic implications. Expert. Opin. Biol. Ther. 2013, 13, S69-S82. [CrossRef] [PubMed]

4. Keats, J.J.; Chesi, M.; Egan, J.B.; Garbitt, V.M.; Palmer, S.E.; Braggio, E.; Van Wier, S.; Blackburn, P.R.; Baker, A.S.; Dispenzieri, A.; et al. Clonal competition with alternating dominance in multiple myeloma. Blood 2012, 120, 1067-1076. [CrossRef]

5. Kumar, S.K.; Lee, J.H.; Lahuerta, J.J.; Morgan, G.; Richardson, P.G.; Crowley, J.; Haessler, J.; Feather, J.; Hoering, A.; Moreau, P. Risk of progression and survival in multiple myeloma relapsing after therapy with imids and bortezomib: A multicenter international myeloma working group study. Leukemia 2012, 26, 149. [CrossRef] [PubMed]

6. Tai, Y.-T.; Anderson, K.C. Antibody-based therapies in multiple myeloma. Bone Marrow Res. $2011,2011$. [CrossRef] [PubMed]

7. Ludwig, D.L.; Pereira, D.S.; Zhu, Z.; Hicklin, D.J.; Bohlen, P. Monoclonal antibody therapeutics and apoptosis. Oncogene 2003, 22, 9097. [CrossRef]

8. Scott, A.M.; Allison, J.P.; Wolchok, J.D. Monoclonal antibodies in cancer therapy. Cancer Immun. Arch. 2012, $12,14$.

9. Lonial, S.; Weiss, B.M.; Usmani, S.Z.; Singhal, S.; Chari, A.; Bahlis, N.J.; Belch, A.; Krishnan, A.; Vescio, R.A.; Mateos, M.V.; et al. Daratumumab monotherapy in patients with treatment-refractory multiple myeloma (sirius): An open-label, randomised, phase 2 trial. Lancet 2016, 387, 1551-1560. [CrossRef]

10. Lonial, S.; Dimopoulos, M.A.; Palumbo, A.; White, D.; Grosicki, S.; Spicka, I.; Walter-Croneck, A.; Moreau, P.; Mateos, M.-V.; Magen-Nativ, H. Eloquent-2: A phase iii, randomized, open-label study of lenalidomide (len)/dexamethasone (dex) with/without elotuzumab (elo) in patients (pts) with relapsed/refractory multiple myeloma (rrmm). J. Clin. Oncol. 2015. [CrossRef]

11. Palumbo, A.; Chanan-Khan, A.A.A.; Weisel, K.; Nooka, A.K.; Masszi, T.; Beksac, M.; Spicka, I.; Hungria, V.T.; Mateos, M.-V.; Mark, T.M. Phase iii randomized controlled study of daratumumab, bortezomib and dexamethasone ( $\mathrm{dvd}$ ) versus bortezomib and dexamethasone (vd) in patients (pts) with relapsed or refractory multiple myeloma (rrmm): Castor study. J. Clin. Oncol. 2016. [CrossRef] 
12. Dimopoulos, M.; Oriol, A.; Nahi, H.; San Miguel, J.; Bahlis, N.; Rabin, N.; Orlowski, R.; Komarnicki, M.; Suzuki, K.; Plesner, T. An open-label, randomised phase 3 study of daratumumab, lenalidomide and dexamethasone (drd) versus lenalidomide and dexamethasone (rd) in relapsed or refractory multiple myeloma (rrmm): Pollux. Haematologica 2016, 101, 342.

13. Dimopoulos, M.A.; Dytfeld, D.; Grosicki, S.; Moreau, P.; Takezako, N.; Hori, M.; Leleu, X.; LeBlanc, R.; Suzuki, K.; Raab, M.S.; et al. Elotuzumab plus pomalidomide and dexamethasone for multiple myeloma. N. Engl. J. Med. 2018, 379, 1811-1822. [CrossRef]

14. Mateos, M.-V.; Dimopoulos, M.A.; Cavo, M.; Suzuki, K.; Jakubowiak, A.; Knop, S.; Doyen, C.; Lucio, P.; Nagy, Z.; Kaplan, P.; et al. Daratumumab plus bortezomib, melphalan and prednisone for untreated myeloma. N. Engl. J. Med. 2018, 378, 518-528. [CrossRef]

15. Munshi, N.C.; Avet-Loiseau, H.; Rawstron, A.C.; Owen, R.G.; Child, J.A.; Thakurta, A.; Sherrington, P.; Samur, M.K.; Georgieva, A.; Anderson, K.C.; et al. Association of minimal residual disease with superior survival outcomes in patients with multiple myeloma: A meta-analysis. JAMA Oncol. 2017, 3, 28-35. [CrossRef]

16. Romano, A.; Conticello, C.; Cavalli, M.; Vetro, C.; La Fauci, A.; Parrinello, N.L.; Di Raimondo, F. Immunological dysregulation in multiple myeloma microenvironment. Biomed. Res. Int. 2014, 2014. [CrossRef]

17. Farkona, S.; Diamandis, E.P.; Blasutig, I.M. Cancer immunotherapy: The beginning of the end of cancer? BMC Med. 2016, 14, 73. [CrossRef]

18. Magarotto, V.; Salvini, M.; Bonello, F.; Bringhen, S.; Palumbo, A. Strategy for the treatment of multiple myeloma utilizing monoclonal antibodies: A new era begins. Leuk. Lymphoma 2016, 57, 537-556. [CrossRef]

19. Chillemi, A.; Zaccarello, G.; Quarona, V.; Ferracin, M.; Ghimenti, C.; Massaia, M.; Horenstein, A.L.; Malavasi, F. Anti-cd38 antibody therapy: Windows of opportunity yielded by the functional characteristics of the target molecule. Mol. Med. 2013, 19, 99-108. [CrossRef]

20. Martin, T.; Hsu, K.; Strickland, S.A.; Glenn, M.; Mikhael, J.; Charpentier, E. A phase i trial of sar650984, a cd38 monoclonal antibody, in relapsed or refractory multiple myeloma. J. Clin. Oncol. 2014, 32. [CrossRef]

21. Richter, J.R.; Martin, T.G.; Vij, R.; Cole, C.; Atanackovic, D.; Zonder, J.A.; Kaufman, J.L.; Mikhael, J.; Bensinger, W.; Dimopoulos, M.A. Updated data from a phase ii dose finding trial of single agent isatuximab (sar650984, anti-cd38 mab) in relapsed/refractory multiple myeloma (rrmm). J. Clin. Oncol. 2016. [CrossRef]

22. Martin, T.G.; Baz, R.; Benson, D.M.; Lendvai, N.; Campana, F.; Charpentier, E.; Vij, R. A phase ib dose escalation trial of sar650984 (anti-cd-38 mab) in combination with lenalidomide and dexamethasone in relapsed/refractory multiple myeloma. Blood 2014, 124, 83. [CrossRef]

23. Martin, T.; Baz, R.; Benson, D.M.; Lendvai, N.; Wolf, J.; Munster, P.; Lesokhin, A.M.; Wack, C.; Charpentier, E.; Campana, F.; et al. A phase $1 \mathrm{~b}$ study of isatuximab plus lenalidomide and dexamethasone for relapsed/refractory multiple myeloma. Blood 2017, 129, 3294-3303. [CrossRef]

24. Lendvai, N.; Vij, R.; Martin, T.G.; Baz, R.; Campana, F.; Mazuir, F.; Charpentier, E.; Benson, D.M. A phase $\mathrm{ib}$ dose-escalation trial of isatuximab (sar650984, anti-cd38 mab) plus lenalidomide and dexamethasone in relapsed/refractory multiple myeloma (rrmm): Interim results from 2 new dose cohorts. J. Clin. Oncol. 2016, 101, 84. [CrossRef]

25. Mikhael, J.; Richardson, P.; Usmani, S.; Raje, N.; Bensinger, W.; Kanagavel, D.; Gao, L.; Ziti-Ljajic, S.; Anderson, K. A phase ib study of isatuximab plus pomalidomide (pom) and dexamethasone (dex) in relapsed/refractory multiple myeloma (rrmm). In Haematologica; Via Giuseppe Belli: Pavia, Italy, 2017; p. 168.

26. Richardson, P.G.; Attal, M.; San Miguel, J.; Campana, F.; Le-Guennec, S.; Hui, A.-M.; Risse, M.-L.; Anderson, K.C. A phase iii, randomized, open-label study of isatuximab (sar650984) plus pomalidomide (pom) and dexamethasone (dex) versus pom and dex in relapsed/refractory multiple myeloma. J. Clin. Oncol. 2017. [CrossRef]

27. Raab, M.S.; Chatterjee, M.; Goldschmidt, H.; Agis, H.; Blau, I.; Einsele, H.; Engelhardt, M.; Ferstl, B.; Gramatzki, M.; Rollig, C.; et al. A phase i/iia study of the cd38 antibody mor202 alone and in combination with pomalidomide or lenalidomide in patients with relapsed or refractory multiple myeloma. Blood 2016, $128,1152$.

28. Tong, A.W.; Stone, M.J. Prospects for cd40-directed experimental therapy of human cancer. Cancer Gene Ther. 2003, 10, 1-13. [CrossRef] 
29. Hussein, M.; Berenson, J.R.; Niesvizky, R.; Munshi, N.; Matous, J.; Sobecks, R.; Harrop, K.; Drachman, J.G.; Whiting, N. A phase i multidose study of dacetuzumab (sgn-40; humanized anti-cd40 monoclonal antibody) in patients with multiple myeloma. Haematologica 2010, 95, 845-848. [CrossRef]

30. Agura, E.; Niesvizky, R.; Matous, J.; Munshi, N.; Hussein, M.; Parameswaran, R.V.; Tarantolo, S.; Whiting, N.C.; Drachman, J.G.; Zonder, J.A. Dacetuzumab (sgn-40), lenalidomide and weekly dexamethasone in relapsed or refractory multiple myeloma: Multiple responses observed in a phase 1b study. Blood 2009, 114, 2870.

31. Bensinger, W.; Maziarz, R.T.; Jagannath, S.; Spencer, A.; Durrant, S.; Becker, P.S.; Ewald, B.; Bilic, S.; Rediske, J.; Baeck, J.; et al. A phase 1 study of lucatumumab, a fully human anti-cd40 antagonist monoclonal antibody administered intravenously to patients with relapsed or refractory multiple myeloma. Br. J. Haematol. 2012, 159, 58-66. [CrossRef]

32. Benson Jr, D.M.; Hofmeister, C.C.; Padmanabhan, S.; Suvannasankha, A.; Jagannath, S.; Abonour, R.; Bakan, C.; Andre, P.; Efebera, Y.; Tiollier, J.; et al. Aphase 1 trial of the anti-kir antibody iph2101 in patients with relapsed/refractory multiple myeloma. Blood 2012, 120, 4324-4333. [CrossRef]

33. Korde, N.; Carlsten, M.; Lee, M.J.; Minter, A.; Tan, E.; Kwok, M.; Manasanch, E.; Bhutani, M.; Tageja, N.; Roschewski, M.; et al. A phase ii trial of pan-kir2d blockade with iph2101 in smoldering multiple myeloma. Haematologica 2014, 99, e81-e83. [CrossRef]

34. Benson, D.M., Jr.; Cohen, A.D.; Jagannath, S.; Munshi, N.C.; Spitzer, G.; Hofmeister, C.C.; Efebera, Y.A.; Andre, P.; Zerbib, R.; Caligiuri, M.A. A phase i trial of the anti-kir antibody iph2101 and lenalidomide in patients with relapsed/refractory multiple myeloma. Clin. Cancer Res. 2015, 21, 4055-4061. [CrossRef]

35. Burton, J.D.; Ely, S.; Reddy, P.K.; Stein, R.; Gold, D.V.; Cardillo, T.M.; Goldenberg, D.M. Cd74 is expressed by multiple myeloma and is a promising target for therapy. Clin. Cancer Res. 2004, 10, 6606-6611. [CrossRef]

36. Kaufman, J.L.; Niesvizky, R.; Stadtmauer, E.A.; Chanan-Khan, A.; Siegel, D.; Horne, H.; Wegener, W.A.; Goldenberg, D.M. Phase i, multicentre, dose-escalation trial of monotherapy with milatuzumab (humanized anti-cd 74 monoclonal antibody) in relapsed or refractory multiple myeloma. Br. J. Haematol. 2013, 163, 478-486. [CrossRef]

37. Schmidmaier, R.; Morsdorf, K.; Baumann, P.; Emmerich, B.; Meinhardt, G. Evidence for cell adhesion-mediated drug resistance of multiple myeloma cells in vivo. Int. J. Biol. Markers 2006, 21, 218-222. [CrossRef]

38. Terpos, E.; Migkou, M.; Christoulas, D.; Gavriatopoulou, M.; Eleutherakis-Papaiakovou, E.; Kanellias, N.; Iakovaki, M.; Panagiotidis, I.; Ziogas, D.C.; Fotiou, D.; et al. Increased circulating vcam-1 correlates with advanced disease and poor survival in patients with multiple myeloma: Reduction by post-bortezomib and lenalidomide treatment. Blood Cancer J. 2016, 6, e428. [CrossRef]

39. Hansson, M.; Gimsing, P.; Badros, A.; Niskanen, T.M.; Nahi, H.; Offner, F.; Salomo, M.; Sonesson, E.; Mau-Sorensen, M.; Stenberg, Y.; et al. A phase i dose-escalation study of antibody bi-505 in relapsed/refractory multiple myeloma. Clin. Cancer Res. 2015, 21, 2730-2736. [CrossRef]

40. Bieghs, L.; Johnsen, H.E.; Maes, K.; Menu, E.; Van Valckenborgh, E.; Overgaard, M.T.; Nyegaard, M.; Conover, C.A.; Vanderkerken, K.; De Bruyne, E. The insulin-like growth factor system in multiple myeloma: Diagnostic and therapeutic potential. Oncotarget 2016, 7, 48732-48752. [CrossRef]

41. Lacy, M.Q.; Alsina, M.; Fonseca, R.; Paccagnella, M.L.; Melvin, C.L.; Yin, D.; Sharma, A.; Enriquez Sarano, M.; Pollak, M.; Jagannath, S.; et al. Phase i, pharmacokinetic and pharmacodynamic study of the anti-insulinlike growth factor type 1 receptor monoclonal antibody cp-751,871 in patients with multiple myeloma. J. Clin. Oncol. 2008, 26, 3196-3203. [CrossRef]

42. Moreau, P.; Cavallo, F.; Leleu, X.; Hulin, C.; Amiot, M.; Descamps, G.; Facon, T.; Boccadoro, M.; Mignard, D.; Harousseau, J.L. Phase i study of the anti insulin-like growth factor 1 receptor (igf-1r) monoclonal antibody, ave1642, as single agent and in combination with bortezomib in patients with relapsed multiple myeloma. Leukemia 2011, 25, 872-874. [CrossRef]

43. Lee, A.S. Glucose-regulated proteins in cancer: Molecular mechanisms and therapeutic potential. Nat. Rev. Cancer 2014, 14, 263-276. [CrossRef] [PubMed]

44. Rasche, L.; Duell, J.; Castro, I.C.; Dubljevic, V.; Chatterjee, M.; Knop, S.; Hensel, F.; Rosenwald, A.; Einsele, H.; Topp, M.S.; et al. Grp78-directed immunotherapy in relapsed or refractory multiple myeloma-results from a phase 1 trial with the monoclonal immunoglobulin m antibody pat-sm6. Haematologica 2015, 100, 377-384. [CrossRef] [PubMed] 
45. Rasche, L.; Menoret, E.; Dubljevic, V.; Menu, E.; Vanderkerken, K.; Lapa, C.; Steinbrunn, T.; Chatterjee, M.; Knop, S.; Dull, J.; et al. A grp78-directed monoclonal antibody recaptures response in refractory multiple myeloma with extramedullary involvement. Clin. Cancer Res. 2016, 22, 4341-4349. [CrossRef] [PubMed]

46. Burger, J.A.; Kipps, T.J. Cxcr4: A key receptor in the crosstalk between tumor cells and their microenvironment. Blood 2006, 107, 1761-1767. [CrossRef]

47. Alsayed, Y.; Ngo, H.; Runnels, J.; Leleu, X.; Singha, U.K.; Pitsillides, C.M.; Spencer, J.A.; Kimlinger, T.; Ghobrial, J.M.; Jia, X.; et al. Mechanisms of regulation of cxcr4/sdf-1 (cxcl12)-dependent migration and homing in multiple myeloma. Blood 2007, 109, 2708-2717. [CrossRef]

48. Fouquet, G.; Guidez, S.; Richez, V.; Stoppa, A.M.; Tourneau, C.L.; Macro, M.; Gruchet, C.; Bobin, A.; Moya, N.; Syshenko, T.; et al. Phase i dose-escalation study of f50067, a humanized anti-cxcr4 monoclonal antibody alone and in combination with lenalidomide and low-dose dexamethasone, in relapsed or refractory multiple myeloma. Oncotarget 2018, 9, 23890-23899. [CrossRef]

49. Voorhees, P.M.; Chen, Q.; Kuhn, D.J.; Small, G.W.; Hunsucker, S.A.; Strader, J.S.; Corringham, R.E.; Zaki, M.H.; Nemeth, J.A.; Orlowski, R.Z. Inhibition of interleukin-6 signaling with cnto 328 enhances the activity of bortezomib in preclinical models of multiple myeloma. Clin. Cancer Res. 2007, 13, 6469-6478. [CrossRef] [PubMed]

50. Voorhees, P.M.; Chen, Q.; Small, G.W.; Kuhn, D.J.; Hunsucker, S.A.; Nemeth, J.A.; Orlowski, R.Z. Targeted inhibition of interleukin-6 with cnto 328 sensitizes pre-clinical models of multiple myeloma to dexamethasone-mediated cell death. Br. J. Haematol. 2009, 145, 481-490. [CrossRef]

51. Brighton, T.; Harrison, S.J.; Ghez, D.; Weiss, B.M.; Kirsch, A.; Magen, H.; Gironella, M.; Oriol, A.; Streetly, M.; Qin, X.; et al. A phase 2, randomized, double-blind, placebo-controlled, multicenter study of siltuximab (anti il-6 monoclonal antibody) in patients with high-risk smoldering multiple myeloma. Blood 2017, 130, 3155.

52. Orlowski, R.Z.; Gercheva, L.; Williams, C.; Sutherland, H.; Robak, T.; Masszi, T.; Goranova-Marinova, V.; Dimopoulos, M.A.; Cavenagh, J.D.; Spicka, I.; et al. A phase 2, randomized, double-blind, placebo-controlled study of siltuximab (anti-il-6 mab) and bortezomib versus bortezomib alone in patients with relapsed or refractory multiple myeloma. Am. J. Hematol. 2015, 90, 42-49. [CrossRef]

53. Voorhees, P.M.; Manges, R.F.; Sonneveld, P.; Jagannath, S.; Somlo, G.; Krishnan, A.; Lentzsch, S.; Frank, R.C.; Zweegman, S.; Wijermans, P.W. A phase 2 multicentre study of siltuximab, an anti-interleukin-6 monoclonal antibody, in patients with relapsed or refractory multiple myeloma. Br. J. Haematol. 2013, 161, 357-366. [CrossRef] [PubMed]

54. Suzuki, K.; Ogura, M.; Abe, Y.; Suzuki, T.; Tobinai, K.; Ando, K.; Taniwaki, M.; Maruyama, D.; Kojima, M.; Kuroda, J.; et al. Phase 1 study in japan of siltuximab, an anti-il-6 monoclonal antibody, in relapsed/refractory multiple myeloma. Int. J. Hematol. 2015, 101, 286-294. [CrossRef] [PubMed]

55. Rajkumar, S.V.; Leong, T.; Roche, P.C.; Fonseca, R.; Dispenzieri, A.; Lacy, M.Q.; Lust, J.A.; Witzig, T.E.; Kyle, R.A.; Gertz, M.A. Prognostic value of bone marrow angiogenesis in multiple myeloma. Clin. Cancer Res. 2000, 6, 3111-3116. [PubMed]

56. Di Raimondo, F.; Azzaro, M.P.; Palumbo, G.; Bagnato, S.; Giustolisi, G.; Floridia, P.; Sortino, G.; Giustolisi, R. Angiogenic factors in multiple myeloma: Higher levels in bone marrow than in peripheral blood. Haematologica 2000, 85, 800-805. [PubMed]

57. Sezer, O.; Jakob, C.; Eucker, J.; Niemöller, K.; Gatz, F.; Wernecke, K.D.; Possinger, K. Serum levels of the angiogenic cytokines basic fibroblast growth factor (bfgf), vascular endothelial growth factor (vegf) and hepatocyte growth factor (hgf) in multiple myeloma. Eur. J. Haematol. 2001, 66, 83-88. [CrossRef]

58. Dankbar, B.; Padró, T.; Leo, R.; Feldmann, B.; Kropff, M.; Mesters, R.M.; Serve, H.; Berdel, W.E.; Kienast, J. Vascular endothelial growth factor and interleukin-6 in paracrine tumor-stromal cell interactions in multiple myeloma. Blood 2000, 95, 2630-2636.

59. Ria, R.; Vacca, A.; Russo, F.; Cirulli, T.; Massaia, M.; Tosi, P.; Cavo, M.; Guidolin, D.; Ribatti, D.; Dammacco, F. A vegf-dependent autocrine loop mediates proliferation and capillarogenesis in bone marrow endothelial cells of patients with multiple myeloma. Thromb. Haemost. 2004, 92, 1438-1445. [CrossRef]

60. Weber, D.M.; Chen, C.; Niesvizky, R.; Wang, M.; Belch, A.; Stadtmauer, E.A.; Siegel, D.; Borrello, I.; Rajkumar, S.V.; Chanan-Khan, A.A.; et al. Lenalidomide plus dexamethasone for relapsed multiple myeloma in north america. N. Engl. J. Med. 2007, 357, 2133-2142. [CrossRef] 
61. Somlo, G.; Lashkari, A.; Bellamy, W.; Zimmerman, T.; Tuscano, J.; O'Donnell, M.; Mohrbacher, A.; Forman, S.; Frankel, P.; Chen, H.; et al. Phase ii randomized trial of bevacizumab versus bevacizumab and thalidomide for relapsed/refractory multiple myeloma: A california cancer consortium trial. Br. J. Haematol. 2011, 154, 533-535. [CrossRef]

62. White, D.; Kassim, A.; Bhaskar, B.; Yi, J.; Wamstad, K.; Paton, V.E. Results from amber, a randomized phase 2 study of bevacizumab and bortezomib versus bortezomib in relapsed or refractory multiple myeloma. Cancer 2013, 119, 339-347. [CrossRef]

63. Moreaux, J.; Legouffe, E.; Jourdan, E.; Quittet, P.; Reme, T.; Lugagne, C.; Moine, P.; Rossi, J.F.; Klein, B.; Tarte, K. Baff and april protect myeloma cells from apoptosis induced by interleukin 6 deprivation and dexamethasone. Blood 2004, 103, 3148-3157. [CrossRef]

64. Bolkun, L.; Lemancewicz, D.; Jablonska, E.; Kulczynska, A.; Bolkun-Skornicka, U.; Kloczko, J.; Dzieciol, J. Baff and april as tnf superfamily molecules and angiogenesis parallel progression of human multiple myeloma. Ann. Hematol. 2014, 93, 635-644. [CrossRef] [PubMed]

65. Rossi, J.F.; Moreaux, J.; Hose, D.; Requirand, G.; Rose, M.; Rouillé, V.; Nestorov, I.; Mordenti, G.; Goldschmidt, H.; Ythier, A.; et al. Atacicept in relapsed/refractory multiple myeloma or active waldenström's macroglobulinemia: A phase i study. Br. J. Cancer 2009, 101, 1051-1058. [CrossRef]

66. Iida, S.; Ogiya, D.; Abe, Y.; Taniwaki, M.; Asou, H.; Maeda, K.; Uenaka, K.; Nagaoka, S.; Ishiki, T.; Conti, I.; et al. Dose-escalation study of tabalumab with bortezomib and dexamethasone in japanese patients with multiple myeloma. Cancer Sci. 2016, 107, 1281-1289. [CrossRef]

67. Raje, N.S.; Moreau, P.; Terpos, E.; Benboubker, L.; Grzasko, N.; Holstein, S.A.; Oriol, A.; Huang, S.Y.; Beksac, M.; Kuliczkowski, K.; et al. Phase 2 study of tabalumab, a human anti-b-cell activating factor antibody, with bortezomib and dexamethasone in patients with previously treated multiple myeloma. Br. J. Haematol. 2017, 176, 783-795. [CrossRef]

68. Menoret, E.; Gomez-Bougie, P.; Geffroy-Luseau, A.; Daniels, S.; Moreau, P.; Le Gouill, S.; Harousseau, J.-L.; Bataille, R.; Amiot, M.; Pellat-Deceunynck, C. Mcl-1l cleavage is involved in trail-r1-and trail-r2-mediated apoptosis induced by hgs-etr1 and hgs-etr2 human mabs in myeloma cells. Blood 2006, 108, 1346-1352. [CrossRef]

69. Belch, A.; Sharma, A.; Spencer, A.; Tarantolo, S.; Bahlis, N.; Doval, D.; Gallant, G.; Klein, J.; Chanan-Khan, A. Results of an international, randomized phase ii clinical trial of bortezomib +/- mapatumumab (trail-r1 agonist monoclonal antibody) for the treatment of relapsed/refractory multiple myeloma (mm). Haematologica 2011, 96, 419-420.

70. Rosenblatt, J.; Avigan, D. Targeting the pd-1/pd-11 axis in multiple myeloma: A dream or a reality? Blood 2017, 129, 275-279. [CrossRef] [PubMed]

71. Keir, M.E.; Butte, M.J.; Freeman, G.J.; Sharpe, A.H. Pd-1 and its ligands in tolerance and immunity. Ann. Rev. Immunol. 2008, 26, 677-704. [CrossRef]

72. Lesokhin, A.M.; Ansell, S.M.; Armand, P.; Scott, E.C.; Halwani, A.; Gutierrez, M.; Millenson, M.M.; Cohen, A.D.; Schuster, S.J.; Lebovic, D.; et al. Nivolumab in patients with relapsed or refractory hematologic malignancy: Preliminary results of a phase ib study. J. Clin. Oncol. 2016, 34, 2698. [CrossRef]

73. Ansell, S.; Gutierrez, M.E.; Shipp, M.A.; Gladstone, D.; Moskowitz, A.; Borello, I.; Popa-Mckiver, M.; Farsaci, B.; Zhu, L.; Lesokhin, A.M.; et al. A phase 1 study of nivolumab in combination with ipilimumab for relapsed or refractory hematologic malignancies (checkmate 039). Blood 2016, 128, 183.

74. Ribrag, V.; Avigan, D.E.; Martinelli, G.; Green, D.J.; Wise-Draper, T.; Posada, J.G.; Vij, R.; Zhu, Y.; Farooqui, M.Z.H.; Marinello, P.; et al. Pembrolizumab monotherapy for relapsed/refractory multiple myeloma: Phase 1b keynote-013 study. Haematologica 2017, 102, 114. [CrossRef] [PubMed]

75. Badros, A.; Hyjek, E.; Ma, N.; Lesokhin, A.; Dogan, A.; Rapoport, A.P.; Kocoglu, M.; Lederer, E.; Philip, S.; Milliron, T.; et al. Pembrolizumab, pomalidomide and low dose dexamethasone for relapsed/refractory multiple myeloma. Blood 2017. [CrossRef] [PubMed]

76. Efebera, Y.A.; Rosko, A.E.; Hofmeister, C.; Benner, J.; Bakan, C.; Stamper, K.; Lamb, T.; Hollie, D.; Sell, M.; Avigan, D.; et al. First interim results of a phase i/ii study of lenalidomide in combination with anti-pd-1 monoclonal antibody mdv9300 (ct-011) in patients with relapsed/refractory multiple myeloma. Blood 2015, 126, 1838.

77. Al-Hujaily, E.M.; Oldham, R.A.A.; Hari, P.; Medin, J.A. Development of novel immunotherapies for multiple myeloma. Int. J. Mol. Sci. 2016, 17, 26. [CrossRef] 
78. Chanan-Khan, A.; Wolf, J.L.; Garcia, J.; Gharibo, M.; Jagannath, S.; Manfredi, D.; Sher, T.; Martin, C.; Zildjian, S.H.; O'Leary, J.; et al. Efficacy analysis from phase i study of lorvotuzumab mertansine (imgn901), used as monotherapy, in patients with heavily pre-treated cd56-positive multiple myeloma-A preliminary efficacy analysis. Blood 2010, 116, 1962.

79. Ailawadhi, S.; Kelly, K.R.; Vescio, R.A.; Jagannath, S.; Wolf, J.; Gharibo, M.; Sher, T.; Bojanini, L.; Kirby, M.; Chanan-Khan, A. A phase i study to assess the safety and pharmacokinetics of single-agent lorvotuzumab mertansine (imgn901) in patients with relapsed and/or refractory cd-56-positive multiple myeloma. Clin. Lymphoma Myeloma Leuk. 2019, 19, 29-34. [CrossRef]

80. Berdeja, J.G.; Ailawadhi, S.; Weitman, S.D.; Zildjian, S.; O'Leary, J.J.; O'Keeffe, J.; Guild, R.; Whiteman, K.; Chanan-Khan, A.A.A. Phase i study of lorvotuzumab mertansine (lm, imgn901) in combination with lenalidomide (len) and dexamethasone (dex) in patients with cd56-positive relapsed or relapsed/refractory multiple myeloma (mm). J. Clin. Oncol. 2011, 29. [CrossRef]

81. Bayer-Garner, I.B.; Sanderson, R.D.; Dhodapkar, M.V.; Owens, R.B.; Wilson, C.S. Syndecan-1 (cd138) immunoreactivity in bone marrow biopsies of multiple myeloma: Shed syndecan-1 accumulates in fibrotic regions. Modern Pathol. 2001, 14, 1052. [CrossRef]

82. Dhodapkar, M.V.; Abe, E.; Theus, A.; Lacy, M.; Langford, J.K.; Barlogie, B.; Sanderson, R.D. Syndecan-1 is a multifunctional regulator of myeloma pathobiology: Control of tumor cell survival, growth and bone cell differentiation. Blood 1998, 91, 2679-2688.

83. Heffner, L.T.; Jagannath, S.; Zimmerman, T.M.; Lee, K.P.; Rosenblatt, J.; Lonial, S.; Lutz, R.J.; Czeloth, N.; Osterroth, F.; Ruehle, M.; et al. Bt062, an antibody-drug conjugate directed against cd138, given weekly for 3 weeks in each 4 week cycle: Safety and further evidence of clinical activity. Blood 2012, 120, 4042.

84. Kelly, K.R.; Siegel, D.S.; Chanan-Khan, A.A.; Somlo, G.; Heffner, L.T.; Jagannath, S.; Zimmerman, T.; Munshi, N.C.; Madan, S.; Mohrbacher, A.; et al. Indatuximab ravtansine (bt062) in combination with low-dose dexamethasone and lenalidomide or pomalidomide: Clinical activity in patients with relapsed/refractory multiple myeloma. Blood 2016, 128.

85. Baeuerle, P.A.; Reinhardt, C. Bispecific t-cell engaging antibodies for cancer therapy. Cancer Res. 2009, 69, 4941-4944. [CrossRef]

86. Hipp, S.; Tai, Y.; Blanset, D.; Deegen, P.; Wahl, J.; Thomas, O.; Rattel, B.; Adam, P.; Anderson, K.; Friedrich, M. A novel bcma/cd3 bispecific $\mathrm{t}$-cell engager for the treatment of multiple myeloma induces selective lysis in vitro and in vivo. Leukemia 2017, 31, 1743. [CrossRef] [PubMed]

87. Seckinger, A.; Delgado, J.A.; Moser, S.; Moreno, L.; Neuber, B.; Grab, A.; Lipp, S.; Merino, J.; Prosper, F.; Emde, M. Target expression, generation, preclinical activity and pharmacokinetics of the bcma-t cell bispecific antibody em801 for multiple myeloma treatment. Cancer Cell 2017, 31, 396-410. [CrossRef] [PubMed]

88. Zou, J.; Chen, D.; Zong, Y.; Ye, S.; Tang, J.; Meng, H.; An, G.; Zhang, X.; Yang, L. Immunotherapy based on bispecific t-cell engager with higg $1 \mathrm{fc}$ sequence as a new therapeutic strategy in multiple myeloma. Cancer Sci. 2015, 106, 512-521. [CrossRef]

89. Chan, W.K.; Kang, S.; Youssef, Y.; Glankler, E.N.; Barrett, E.R.; Carter, A.M.; Ahmed, E.H.; Prasad, A.; Chen, L.; Zhang, J. A cs1-nkg2d bispecific antibody collectively activates cytolytic immune cells against multiple myeloma. Cancer Immunol. Res. 2018, 6, 776-787. [CrossRef]

90. Ramadoss, N.S.; Schulman, A.D.; Choi, S.-H.; Rodgers, D.T.; Kazane, S.A.; Kim, C.H.; Lawson, B.R.; Young, T.S. An anti-b cell maturation antigen bispecific antibody for multiple myeloma. J. Am. Chem. Soc. 2015, 137, 5288-5291. [CrossRef] [PubMed]

91. A Trial of tti-622 in Patients with Advanced Relapsed or Refractory Lymphoma or Myeloma. Available online: https://clinicaltrials.gov/ct2/show/NCT03530683. (accessed on 1 May 2018).

92. Botta, C.; Gullà, A.; Correale, P.; Tagliaferri, P.; Tassone, P. Myeloid-derived suppressor cells in multiple myeloma: Pre-clinical research and translational opportunities. Front. Oncol. 2014, 4, 348. [CrossRef]

93. Hideshima, T.; Mitsiades, C.; Tonon, G.; Richardson, P.G.; Anderson, K.C. Understanding multiple myeloma pathogenesis in the bone marrow to identify new therapeutic targets. Nat. Rev. Cancer 2007, 7, 585. [CrossRef]

94. Brown, R.D.; Pope, B.; Murray, A.; Esdale, W.; Sze, D.M.; Gibson, J.; Ho, P.J.; Hart, D.; Joshua, D. Dendritic cells from patients with myeloma are numerically normal but functionally defective as they fail to up-regulate cd80 (b7-1) expression after hucd40lt stimulation because of inhibition by transforming growth factor- $\beta 1$ and interleukin-10. Blood 2001, 98, 2992-2998. [CrossRef] 
95. Palumbo, A.; Mateos, M.-V.; San Miguel, J.; Shah, J.; Thompson, S.; Marinello, P.M.; Jagannath, S. Keynote-185: A randomized, open-label phase 3 study of pembrolizumab in combination with lenalidomide and low-dose dexamethasone in newly diagnosed and treatment-naive multiple myeloma (mm). J. Clin. Oncol. 2016. [CrossRef]

96. Badros, A.Z.; Kocoglu, M.H.; Ma, N.; Rapoport, A.P.; Lederer, E.; Philip, S.; Lesho, P.; Dell, C.; Hardy, N.M.; Yared, J. A phase ii study of anti pd-1 antibody pembrolizumab, pomalidomide and dexamethasone in patients with relapsed/refractory multiple myeloma (rrmm). Blood 2015, 126, 506.

97. Lesokhin, A.M.; Ansell, S.M.; Armand, P.; Scott, E.C.; Halwani, A.; Gutierrez, M.; Millenson, M.M.; Cohen, A.D.; Schuster, S.J.; Lebovic, D. Preliminary results of a phase i study of nivolumab (bms-936558) in patients with relapsed or refractory lymphoid malignancies. Blood 2014, 124, 291.

98. González-Calle, V.; Keane, N.; Braggio, E.; Fonseca, R. Precision medicine in myeloma: Challenges in defining an actionable approach. Clin. Lymphoma Myeloma Leuk. 2017, 17, 621-630.

99. Nishihori, T.; Shain, K. Insights on genomic and molecular alterations in multiple myeloma and their incorporation towards risk-adapted treatment strategy: Concise clinical review. Int. J. Genom. 2017, 2017. [CrossRef]

100. Nijhof, I.S.; Casneuf, T.; van Velzen, J.; van Kessel, B.; Axel, A.E.; Syed, K.; Groen, R.W.; van Duin, M.; Sonneveld, P.; Minnema, M.C. Cd38 expression and complement inhibitors affect response and resistance to daratumumab therapy in myeloma. Blood 2016, 128, 959-970. [CrossRef]

101. Zhang, X.-D.; Baladandayuthapani, V.; Lin, H.; Mulligan, G.; Li, B.; Esseltine, D.-L.W.; Qi, L.; Xu, J.; Hunziker, W.; Barlogie, B. Tight junction protein 1 modulates proteasome capacity and proteasome inhibitor sensitivity in multiple myeloma via egfr/jak1/stat3 signaling. Cancer Cell 2016, 29, 639-652. [CrossRef]

102. Zhu, Y.X.; Braggio, E.; Shi, C.-X.; Bruins, L.A.; Schmidt, J.E.; van Wier, S.; Chang, X.-B.; Bjorklund, C.C.; Fonseca, R.; Bergsagel, P.L. Cereblon expression is required for the anti-myeloma activity of lenalidomide and pomalidomide. Blood 2011, 118, 4771-4779. [CrossRef]

103. Paiva, B.; van Dongen, J.J.; Orfao, A. New criteria for response assessment: Role of minimal residual disease in multiple myeloma. Blood 2015, 125, 3059-3068. [CrossRef]

(C) 2019 by the authors. Licensee MDPI, Basel, Switzerland. This article is an open access article distributed under the terms and conditions of the Creative Commons Attribution (CC BY) license (http://creativecommons.org/licenses/by/4.0/). 